\title{
STRATEGY FORMULATION FOR THE SUSTAINABLE DEVELOPMENT OF SMART CITIES: A CASE STUDY OF NANJING, CHINA
}

\author{
Jingfeng YUAN (iD ${ }^{1,}$, Hong XIE ${ }^{1}$, Dujuan $\mathrm{YANG}^{2}$, Xiaer XIAHOU ${ }^{1}$, \\ Mirosław J. SKIBNIEWSKI ${ }^{3,4,5}$, Wei HUANG ${ }^{6}$ \\ ${ }^{1}$ Department of Construction and Real Estate, School of Civil Engineering, Southeast University, 210096, \\ Nanjing, P. R. China \\ ${ }^{2}$ Department of Built Environmental, Technische Universiteit Eindhoven, 5600 MB Eindhoven, The Netherlands \\ ${ }^{3}$ Department of Civil and Environmental Engineering, University of Maryland, College Park, MD 20742, USA \\ ${ }^{4}$ Institute for Theoretical and Applied Informatics, Polish Academy of Science, Gliwice 44100, Poland \\ ${ }^{5}$ Chaoyang University of Technology, 41349, Taichung, Taiwan \\ ${ }^{6}$ School of Civil Engineering, Sanjiang University, 210012, Nanjing, P. R. China
}

Received 18 October 2019; accepted 19 January 2020

\begin{abstract}
Smart cities possess huge potential in future urban development. However, the critical problems in developing sustainable smart cities in China are the lack of clear strategies and effective strategy planning tools. Therefore, reasonable plans and strategies play important roles in helping the government develop sustainable smart cities. In this study, 16 SWOT (Strength, Weakness, Opportunity, and Threat) factors were identified. According to a structured questionnaire survey about SWOT factors, an integrated method, composed of SWOT and AHP (analytic hierarchy process) was conducted. A case study was conducted in Nanjing, China. The most powerful facilitators (strengths and opportunities) and the most powerful obstacles (weaknesses and threats) for developing Smart Nanjing City (SNC) were identified. The strategic intensity and value of the elements were confirmed. Moreover, proactive strategies were proposed including strengthening intelligent clusters, establishing governance ecosystem, and providing integrated services for SNC, which can be considered as policy suggestions for SNC, providing hybrid strategies for a planning approach integrating bottom-up and top-down design to develop smart cities, as a reference for other global cities. Moreover, the proposed AHP-SWOT hybrid method can be used as an effective quantitative strategy planning tool to help other authorities determine appropriate strategies for developing smart cities.
\end{abstract}

Keywords: smart cities, SWOT, AHP, strategy formulation, sustainable development.

\section{Introduction}

With the continuous development of human society, a future city should accommodate larger populations. The United Nations (2014) predicted that the level of urbanization would reach about two-thirds by 2050 . Urbanization in developing countries is faster than that in the rest of the world (Yin et al., 2015). The urbanization rate in China has changed from $40.53 \%$ to $57.35 \%$ in the past 10 years, based on the reports by the National Bureau of Statistics (2016). During the process of rapid urbanization, a series of "urban disease" symptoms have emerged and become increasingly prominent (e.g. traffic congestion, hazy weather, construction waste, etc.), which have seriously hindered the healthy and sustainable development of cities (Sta, 2017; Wu et al., 2016). With the rapid evo- lution, application and promotion of New Generation of Information Technology (NGIT) ${ }^{1}$, such as cloud computing, Internet of Things (IoT), etc., a smart city is thought to be an effective solution to cope with "urban disease" and promote sustainable urban development (Silva et al., 2018; Wann-Ming, 2019).

Nowadays, more and more cities in China are devoted to developing smart cities. In 2012, the Ministry of Housing and Urban-Rural Development (MOHURD) issued two files: "Temporary Administrative Measures for a Smart City Pilot in China" and the "Indicator System for a Smart City Pilot in China" (MOHURD, 2012), which promoted

\footnotetext{
1 Abbreviations and full names for the special nouns in this paper are listed in Notations.
}

${ }^{*}$ Corresponding author. E-mail: jingfeng-yuan@seu.edu.cn 
the pilot work on the national smart cities. In 2014, the "National New Urbanization Plan (2014-2020)" issued by State Council (SC) made a clear proposal for accelerating the development of smart cities (State Council, 2014). In 2015, the "Guidelines on Promoting the Healthy Development of Smart Cities" put forward the goal of building new and distinctive smart cities for the year 2020 in China, focusing on overall planning, institutional innovation, mechanism innovation, and network security vulnerabilities (National Development and Reform Commission et al., 2015). According to the guidelines, the development of smart cites also facilitates urban transformation and improvement of the environment, public services and social security in different cities in China. China has launched a series of policies to promote the development of smart cities. From 2013 to 2014, MOHURD published 3 batches of plans for national smart cities, a total of 290 pilot cities were launched (MOHURD, 2013a, 2013b, 2014). The total investment in the development of smart cities has exceeded 700 billion CNY, as is shown in Figure 1 (Shi, 2016). Huge investments in smart cities derive from the government's belief that the old development polices can no longer guarantee sustainable development of cities. The local governments in China are eager to find new ways to develop the economy. The concept of a smart city gives them enlightenment: developing smart cities is a sustainable way to achieve China's new urbanization.

Therefore, smart cities are emerging as a fast-growing topic for different cities in China, and has become a type of label for urban development. There are many strategies for developing smart cities around the world and researchers have undertaken many studies on their design and implementation processes (Silva et al., 2018). Lee et al. (2014) proposed a conceptual framework and eight "stylized facts" for managers to build an effective and sustainable smart city. Luan and Li (2015) make suggestions on how to build smart cities scientifically from the perspective of local government management and technology through qualitative analysis. The analysis of the process to make smarter cities highlights three elements from smart city projects: the scale of the infrastructure; policy areas and scope; and key performance indicators to assess the success and progress of smart city projects (Bilbil,
2017). With regard to how to promote the development of smart cities, Mora et al. (2019) put forward different hypotheses and tested them through a multi-case analysis of European best practices, and finally formulated a set of strategic principles to guide the development of smart cities for Europe. Silva et al. (2018) identified opportunities and challenges for sustainable smart city development. $\mathrm{Vu}$ and Hartley (2018) proposed a policy framework to guide and evaluate smart city initiatives for developing countries. The conditions such as resources, demographics, political, social and growing problems of the city had a major impact on the eventual formulation of strategies and guidelines for developing smart cities (BednarskaOlejniczak et al., 2019).

However, most strategies for developing smart cities are formulated without considering bottom-up approaches (Sharifi, 2019), which cannot meet the local needs, and inadequately consider privacy and security issues (Angelidou, 2017). In the top-level design for developing a quite efficient smart city, citizens can suffer huge economic losses due to the neglect of information about security (Li et al., 2018). Due to the lack of a clear strategy for developing sustainable smart cities, there is a distorted understanding of urban development (Vu \& Hartley, 2018), such as, duplicated construction, isolated information islands, lack of scientific top-level design, lack of standards support, etc. These issues are very common. In order to realize the sustainable and healthy development of smart cities in China, significant top-down and bottom-up designs will take an important role in promoting smart city development in terms of differentiation characteristics, accelerating wisdom about technological innovation and industrial development, and promoting the effective integration of smart cities.

Another critical problem for developing sustainable smart cities is the lack of effective strategy planning tools (Mora et al., 2019). Many prior studies adopted qualitative methods (e.g. case studies, interviews, and SMART models), analyzing the strategies to develop smart cities (Ben Letaifa, 2015). This research aims to provide a quantitative path analysis for the strategic formulation of sustainable developments for smart cities by analyzing the advantages, disadvantages, opportunities and threats of their current

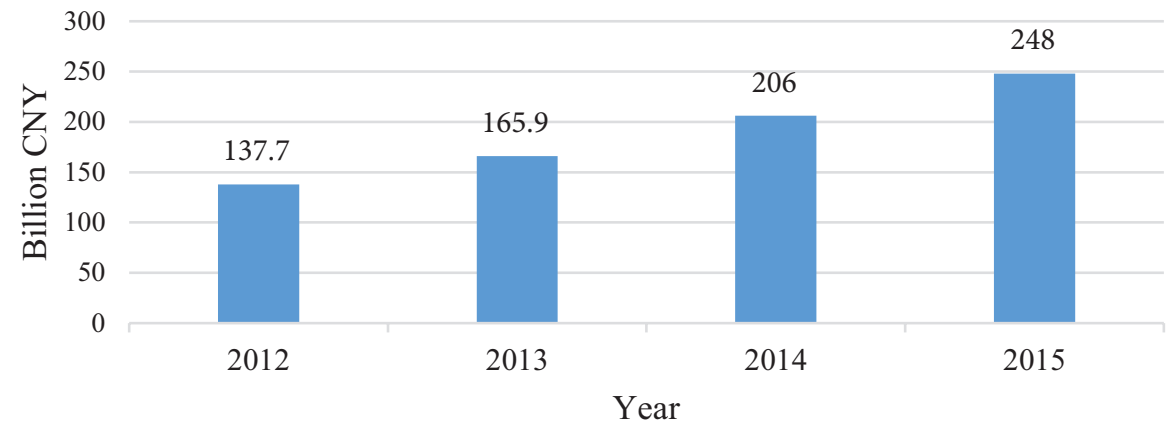

Figure 1. Investment on development smart cities in China 
development. In this case, the SWOT (Strength, Weakness, Opportunity, and Threat) analysis is an appropriate tool to identify key variables currently affecting the development of smart cities, highlight the internal (strengths and weaknesses) and external (opportunities and threats) factors that determine these options, and provide strong support for the decision makers (Şeker \& Özgürler, 2012). However, the SWOT analysis is questioned because of the lack of quantitative testing, this being its technical limitation (Kurttila et al., 2000). To overcome this limitation, Jeon and Kim (2011) proposed a hybrid method, called SWOT-AHP, to enhance the availability and application of the SWOT analysis, by using AHP (analytic hierarchy process) method. AHP is a decision-making approach that includes multiple attributes and has been widely used in formulating multi-objective decisions to resolve quantitative problems for independent factors (Saaty, 1977). The hybrid method SWOT-AHP makes up for the deficiencies in SWOT qualitative analysis. It has been utilized for quantitatively analyzing strategic planning in different areas, including forest management (Kurttila et al., 2000), the development of the machine tool industry (Shinno et al., 2006), tourism management (Jeon \& Kim, 2011), and land use (Polat et al., 2017), etc., which are the foundation for this study, establishing a quantitative analysis method for strategy formulation for smart cities.

As one of the first pilot smart cities, Smart Nanjing City's (SNC) development has been initiated early in China. It has achieved the top level in design, infrastructure development, city management, promotion of information technology and the development of intelligent industry (Liu, 2015). Recently, SNC has been ranked as a leading city according to "The Sixth (2016) Evaluation Report on the Development Level of Smart Cities in China" (Information Research Center of Chinese Academy of Social Sciences, 2016). In addition, the "Approval for the establishment of 'Nanjing Jiangbei New Area"' was issued by SC (2015). Since then, the development of Nanjing Jiangbei New Area has been promoted as part of the national strategy and the government is committed to building a smart city. The experiences of Nanjing will not only help other cities at the same level (e.g. Hangzhou, Suzhou, Jinan etc.) to develop smart cities, but will also provide useful lessons and references for other smart cities in China and elsewhere.

\section{Research methodology}

In this paper, the hybrid method of SWOT-AHP is adopted to analyze the status of smart city development, and to develop strategies for the government in China. SNC is used as an example in this study to illustrate the process of formulating the strategies. The specific implementation process of the SWOT-AHP hybrid method is shown in Figure 2. The development of smart cities cannot be the solution to all of a city's problems. Actually, every pilot city should analyze the actual local situation and seek the direction of future development. The proposed common

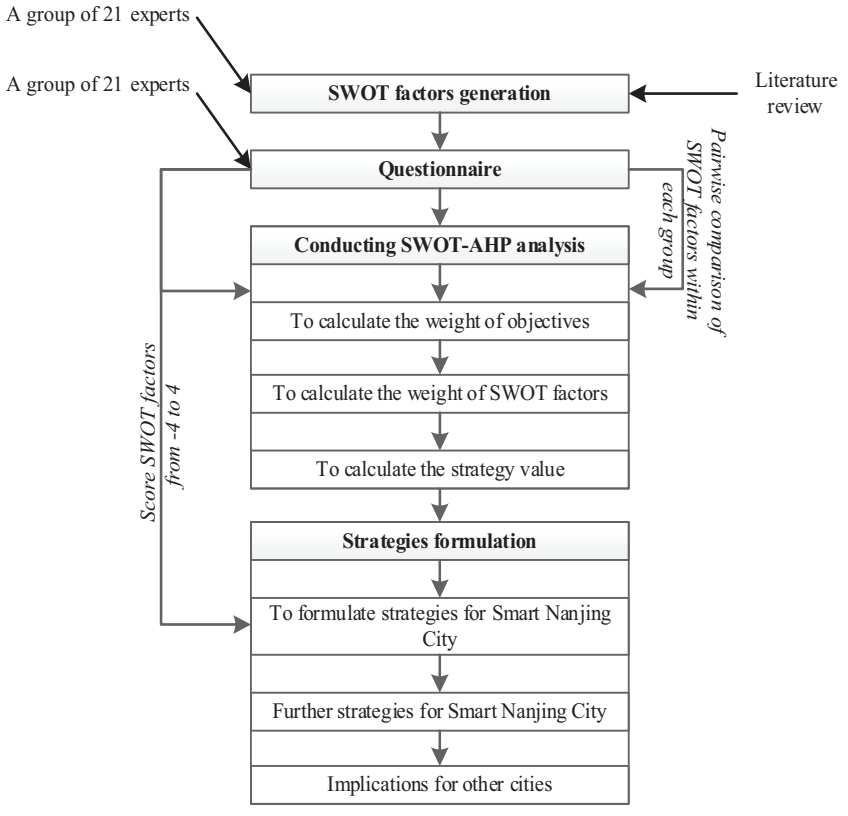

Figure 2. The procedure to formulate strategies

strategic planning tool, the SWOT-AHP hybrid method, may also be applicable to other cities and may provide a strategic analysis for each city.

\subsection{Research survey}

To obtain the significance of SWOT factors, a questionnaire survey was conducted from August 20, 2016 to October 20, 2016. The questionnaire was provided to the experts one by one and face to face, which was helpful when figuring out their doubts, to ensure that the results are more reliable. Smart city is a governance system that coordinates multiple stakeholders and emphasizes the participation of different actors. Therefore, a smart city development should incorporate the opinions of stakeholders. In order to avoid the problems caused by the public's lack of reasonable knowledge about smart cities, the general public are not surveyed, but the opinions of researchers are used instead. Some prior studies in this field are also designed in this way to investigate the opinions of different stakeholders (Sharifi, 2019; Starr et al., 2019). In order to have a common understanding of smart cities and guarantee the validity and scientificity of the questionnaire, the experts should have solid theoretical foundations (IoT, cloud computing, urban planning, urban management, etc.) or rich practical experience in different areas (intelligent transportation, smart grids, intelligent government management, intelligence services, etc.). To generate a reliable and forwarding-looking strategy for SNC development, the survey targeted officials and researchers with 10 years' experience in the area of smart cities in Nanjing, and the education background of all the experts is undergraduate and above. In the end, $21 \mathrm{ex}$ perts agreed to take the questionnaire. Eight people came from Nanjing government departments, nine people came 
from the suppliers or relevant enterprises of intelligence services in Nanjing, and four people came from the universities or related scientific research institutes in Nanjing. The sample size is not an important issue in performing AHP, for the researchers could not agree on the number of experts needed for a reliable AHP analysis (Ghimire \& Kim, 2018). Since the AHP method can perform reliable analysis even when the number of experts is small, this study does not consider a small sample size as a constraint condition. Each expert carried out an in-depth analysis and evaluation combined with his or her own professional background.

The questionnaire contains two parts. The first part is about the investigation of SWOT factors in smart cities. To be more specific, a 5-level scale is adopted to collect the experts' viewpoint for every SWOT factor from 0 to 4 (Table 1). No matter how big the advantage ( $\mathrm{S}$ and $\mathrm{O}$ ) is, it will promote the sustainable development of smart cities, while the disadvantage ( $\mathrm{W}$ and $\mathrm{T}$ ), no matter how big or small, will hinder the development of smart cities. So, the score for $\mathrm{W}$ and $\mathrm{T}$ is minus.

In the second part, pairwise comparison is conducted to compare every two factors in the same SWOT group in pairs to judge their relative importance and to grade them based on a 5-level scale. Actually, pairwise comparisons usually involve difficulties in making judgments across the 5 numbers, which leads to biases. In this case, selecting experts with a solid theoretical foundation, rich practical experience and strong professional background was helpful to reduce these biases. The key issues for comparisons are: (1) Which factors are more important from the perspective of opportunity, threat, weakness, and strength, and (2) How much is the degree of importance. The local priorities for these factors are calculated using the eigenvalue method, where the comparisons are the input, based on which of the global priorities for each factor in all the factors also can be obtained. These matters of priority reflect the understanding of policymakers about the significance of these factors. The paired comparison matrix $A$ will be conducted as shown in Equation (1), where $a_{i j}$ is of local relative importance for $i$ to $j$ in every group of SWOT factors; and $a_{j i}=1 / a_{i j}$. Hence, if $j=i, a_{j i}=a_{i j}=1$. In this study, the letter $w$ is used to represent the weights of the 16 SWOT factors affecting the development of SNC. The weights can reflect the significances of different SWOT factors to help the government compare different strate-
Table 2. Measurement of relative importance

\begin{tabular}{|l|c|}
\hline \multicolumn{1}{|c|}{ Definition } & Score \\
\hline Equal important & 1 \\
\hline Obvious important & 3 \\
\hline Extreme important & 5 \\
\hline Between $1,3,5$ & 2,4 \\
\hline
\end{tabular}

gies and make decisions about developing smart cities. In detail, the value of $w_{i}$ can range from 1 to 5 (Table 2).

$$
A=\left(a_{i j}\right)=\left[\begin{array}{cccc}
a_{11} & a_{12} & \cdots & a_{1 n} \\
a_{21} & a_{22} & \cdots & a_{2 n} \\
\vdots & \vdots & \ddots & \vdots \\
a_{n 1} & a_{n 2} & \cdots & a_{n n}
\end{array}\right]=\left[\begin{array}{cccc}
1 & w_{1} / w_{2} & \cdots & w_{1} / w_{n} \\
w_{2} / w_{1} & 1 & \cdots & w_{2} / w_{n} \\
\vdots & \vdots & \ddots & \vdots \\
w_{n} / w_{n} & w_{n} / w_{2} & \cdots & 1
\end{array}\right]
$$

Based on the pairwise comparison, the opinions on SWOT factors of the respondents investigated through the survey can be integrated. Furthermore, factor weights will be used to determine the intensity of different SWOT groups for every expert. Moreover, the intensity of the strategic goal can be analyzed when integrating the opinions of each respondent. Thus, the formulation of the strategy can be further discussed, based on the results of the final strategy value.

\subsection{SWOT-AHP method}

First, the hierarchy structure for AHP is established using the factors obtained by the SWOT analysis, which can be shown in Figure 3.

The hierarchy structure contains three levels, which are the levels of the objectives, factors, and strategies. The parameters of the different levels are shown in Table 3.

$V$ is the global strategic value for the strategies; therefore, $V$ can be acquired from Equation (2):

$$
V=w_{s} \sum_{i=1}^{4} w_{S i} U_{S i}+w_{W} \sum_{i=1}^{4} w_{W i} U_{W i}+w_{O} \sum_{i=1}^{4} w_{O i} U_{O i}+w_{T} \sum_{i=1}^{4} w_{T i} U_{T i},
$$

where: $V$ is derived from one questionnaire according to the opinions of one expert.

\begin{tabular}{|c|c|c|c|c|c|}
\hline & Definition & Score & & Definition & Score \\
\hline \multirow[t]{5}{*}{$\mathrm{S}$ and $\mathrm{O}$} & No advantage & 0 & \multirow[t]{5}{*}{$\mathrm{W}$ and $\mathrm{T}$} & No disadvantage & 0 \\
\hline & Ordinary advantage & 1 & & General disadvantage & -1 \\
\hline & Good advantage & 2 & & Large disadvantage & -2 \\
\hline & Major advantage & 3 & & Severe disadvantage & -3 \\
\hline & Absolute advantage & 4 & & Extreme disadvantage & -4 \\
\hline
\end{tabular}

Table 1. Measurement of importance 


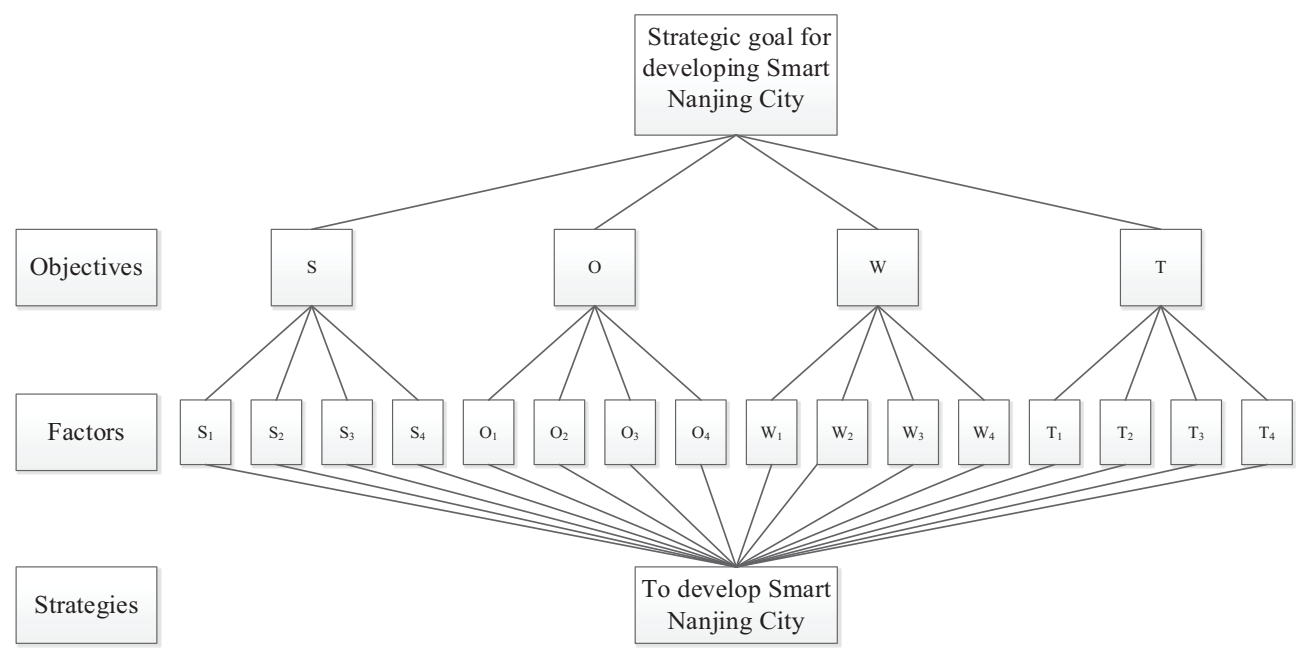

Figure 3. The AHP hierarchy structure for SWOT factors

Table 3. The parameters when determining the strategic goal

\begin{tabular}{|l|l|l|}
\hline \multicolumn{1}{|c|}{ Level } & \multicolumn{1}{|c|}{ Parameters } & \multicolumn{1}{c|}{ Explanation } \\
\hline Objectives & $w_{S}, w_{W}, w_{O}$, and $w_{T}$ & $\begin{array}{l}\text { The significance of the different SWOT groups } \\
\text { (There are 4 groups in this paper, the } S \text { group is comprised of strengths, the } W \\
\text { group is comprised of weaknesses, the } O \text { group is comprised of opportunities, } \\
\text { the } T \text { group is comprised of threats) }\end{array}$ \\
\hline Factors & $\begin{array}{l}w_{S 1}-w_{S 4}, w_{W 1}-w_{W 4}, w_{O 1}-w_{O 4}, \\
\text { and } w_{T 1}-w_{T 4}\end{array}$ & The local significance of different SWOT factors in the same group \\
\hline Strategies & $\begin{array}{l}U_{S 1}-U_{S 4}, U_{W 1}-U_{W 4}, U_{O 1}-U_{O 4}, \\
\text { and } U_{T 1}-U_{T 4}\end{array}$ & The scoring for different SWOT factors in the questionnaire survey \\
\hline
\end{tabular}

Next, the questionnaire survey can collect the opinions of all respondents for different SWOT factors, which can be used to calculate the importance of the SWOT groups from Equation (3):

$$
\begin{aligned}
& w_{s}=\frac{\left|\sum_{r=1}^{21} \sum_{i=1}^{4} U_{r \mathrm{Si}}\right|}{\left|\sum_{r=1}^{21} \sum_{i=1}^{4} U_{r \mathrm{Si}}\right|+\left|\sum_{r=1}^{21} \sum_{i=1}^{4} U_{r W \mathrm{i}}\right|+\left|\sum_{r=1}^{21} \sum_{i=1}^{4} U_{r O \mathrm{i}}\right|+\left|\sum_{r=1}^{21} \sum_{i=1}^{4} U_{r T \mathrm{i}}\right|} ; \\
& w_{w}=\frac{\left|\sum_{r=1}^{21} \sum_{i=1}^{4} U_{r W \mathrm{i}}\right|}{\left|\sum_{r=1}^{21} \sum_{i=1}^{4} U_{r \mathrm{i}}\right|+\left|\sum_{r=1}^{21} \sum_{i=1}^{4} U_{r W \mathrm{i}}\right|+\left|\sum_{r=1}^{21} \sum_{i=1}^{4} U_{r \mathrm{O}}\right|+\left|\sum_{r=1}^{21} \sum_{i=1}^{4} U_{r T \mathrm{i}}\right|} ; \\
& w_{o}=\frac{\left|\sum_{r=1}^{21} \sum_{i=1}^{4} U_{r O \mathrm{i}}\right|}{\left|\sum_{r=1}^{21} \sum_{i=1}^{4} U_{r \mathrm{Si}}\right|+\left|\sum_{r=1}^{21} \sum_{i=1}^{4} U_{r W \mathrm{i}}\right|+\left|\sum_{r=1}^{21} \sum_{i=1}^{4} U_{r O \mathrm{i}}\right|+\left|\sum_{r=1}^{21} \sum_{i=1}^{4} U_{r T \mathrm{i}}\right|} ; \\
& w_{T}=\frac{\left|\sum_{r=1}^{21} \sum_{i=1}^{4} U_{r T \mathrm{i}}\right|}{\left|\sum_{r=1}^{21} \sum_{i=1}^{4} U_{r S \mathrm{i}}\right|+\left|\sum_{r=1}^{21} \sum_{i=1}^{4} U_{r W \mathrm{i}}\right|+\left|\sum_{r=1}^{21} \sum_{i=1}^{4} U_{r O \mathrm{i}}\right|+\left|\sum_{r=1}^{21} \sum_{i=1}^{4} U_{r T \mathrm{i}}\right|}
\end{aligned}
$$

where: $U_{r S i}, U_{r W i}, U_{r O i}$, and $U_{r T i}$ indicates the scoring of the $r^{\text {th }}$ respondent on the $i^{\text {th }} \mathrm{S}, \mathrm{W}, \mathrm{O}$, and $\mathrm{T}$ factor, separately.
The eigenvalue technique is further used to estimate the priority or weight when there are inconsistencies in matrix $A$, which can be acquired from Equation (4), as shown in below:

$$
\left(A-\lambda_{\max } I\right) w=0 .
$$

Equation (4) can be converted into Equation (5):

$$
\lambda_{\max }=\frac{1}{w} \sum_{j=1}^{n} a_{i j} w_{j}, \sum_{i=1}^{n} w_{i}=1 .
$$

where: $\lambda_{\max }=$ matrix $A$ 's maximum eigenvalue; $w=$ weight vector; and $I=$ matrix of identity, which provided the detailed calculation for $\lambda_{\max }$ and $w$ (Saaty \& Vargas, 2012). Therefore, the following steps can describe the details of the calculation.

Step A: To figure out the local importance of $w_{S i}$ from Equation (6):

$$
w_{S i}=\frac{\overline{W_{i}}}{\sum_{i=1}^{4} \bar{W}_{i}},
$$

where

$$
\bar{W}=\sqrt[4]{\prod_{j=1}^{4} s_{i j}}(i=1,2,3,4) .
$$


Step B: The maximum eigenvalue $\lambda_{\max }$ for matrix $S$ can be acquired from Equation (7):

$$
\lambda_{\max }=\sum_{i=1}^{4} \frac{\sum_{j=1}^{4} s_{i j} \cdot \omega_{s i}\left(i^{\prime}=1,2,3,4\right)}{4 \cdot \omega_{s i}} .
$$

Step C: The consistency index for a comparison matrix can be provided according to Equations (8) and (9). CR is the consistency ratio, $C I$ is the consistency index, and $R I$ is the random consistency index. When $n=4, R I$ is 0.90 , while the value of $C R$ should be 10 percent or less, which can be considered acceptable (Saaty \& Vargas, 2012).

$$
\begin{aligned}
& C R=\frac{C I}{R I} ; \\
& C I=\left(\lambda_{\max }-n\right) /(n-1) .
\end{aligned}
$$

Step D: The intensities for each SWOT group can be calculated through the scoring of the SWOT factors from one survey questionnaire, which are obtained from Equation (10).

$$
\begin{aligned}
& I_{S}=w_{s} \sum_{i=1}^{4} I_{S i}, I_{W}=w_{W} \sum_{i=1}^{4} I_{W i}, I_{O}=w_{O} \sum_{i=1}^{4} I_{O i}, \\
& I_{T}=w_{T} \sum_{i=1}^{4} I_{T i},
\end{aligned}
$$

where: $I_{S i}=w_{S i} \cdot U_{S i}, \quad I_{W i}=w_{W i} \cdot U_{W i}, I_{O i}=w_{O i} \cdot U_{O i}$, $I_{T i}=w_{T i} \cdot U_{T i}$.

Finally, this study sought to obtain the intensities of the SWOT factors, based on the integration of the opinions for all 21 respondents. By using the average value of intensities for the SWOT factors to calculate the SWOT groups' intensities, $V_{F}$, which means the final strategic value, can be acquired from Equation (11):

$$
\begin{aligned}
& V_{F}=I_{F S}+I_{F W}+I_{F O}+I_{F T}= \\
& w_{S} \cdot I_{m S i}+w_{W} \cdot I_{m W i}+w_{O} \cdot I_{m O i}+w_{T} \cdot I_{m T i},
\end{aligned}
$$

where all the experts' final group intensities can be represented by $I_{F S}, I_{F W}, I_{F O}$, and $I_{F T}$; and the average factor intensities within each group are described by $I_{m S i}, I_{m W i}$, $I_{m O i}$, and $I_{m T i}$; and

$$
\begin{aligned}
I_{m S i} & =\frac{\sum_{r=1}^{21} \sum_{i=1}^{4} w_{S i} U_{r S i}}{21}, I_{m W i}=\frac{\sum_{r=1}^{21} \sum_{i=1}^{4} w_{W i} U_{r W i}}{21}, \\
I_{m O i} & =\frac{\sum_{r=1}^{21} \sum_{i=1}^{4} w_{O i} U_{r O i}}{21}, I_{m T i}=\frac{\sum_{r=1}^{21} \sum_{i=1}^{4} w_{T i} U_{r T i}}{21} .
\end{aligned}
$$

\section{Identification of SWOT factors}

Identification of SWOT factors is important because it can inform later steps in the strategy formulation to achieve the specific objectives for developing smart cities. A SWOT analysis is a strategic balance sheet of a specific city, which includes the strengths, the weaknesses, the opportunities, and the threats of the city. The strengths are to enable the government to fulfill its mission of developing smart cities, according to which sustainable success can be achieved. The weaknesses are preventing the government from completing the tasks of developing smart cities. Thus, the weaknesses can affect growth and success when developing smart cities. Opportunities could be influenced by the external environment, under which the city operates. These can happen when cities are able to use the conditions in their environment to plan and implement strategies that make them more competitive and sustainable. When external environment conditions endanger the sustainable and healthy development of the city, there will be threats. Threats exacerbate vulnerability when they are related to weaknesses (Polat et al., 2017).

According to Giest (2017), the fundamental factors influencing the development of smart cities can be concluded to include the impacts of the macro environment, the demands of multiple stakeholders, and the current situation of the specific city in a smart city development. For the impacts of the macro environment, external opportunities and threats can be identified when considering the impacts of politics, economics, society, and the natural environment (Matthews, 2004). How to strengthen the capability and resilience of cities, when dealing with constantly changing environments, should be critical for developing smart cities. For the demands of different stakeholders, external opportunities and threats, as well as internal strengths and weaknesses, can be identified when placing the demands of government, enterprises, general public, and research institutes into consideration (Ahvenniemi et al., 2017). How to meet the requirements of different stakeholders innovatively should be the key task in developing smart cities. For the current status of a specific city in developing smart cities, the internal strengths and weaknesses can be identified when considering the foundations of technologies, services, industries, and applications related to the development of smart cities (Paliwal, 2006). How to develop competitive intelligent products and enhance the intelligence level of the infrastructure should be crucial for the long-term success of any urban development. Therefore, the universal SWOT analysis framework for path analyzing is shown in Figure 4, which reveals how to get different factors of $\mathrm{S}, \mathrm{W}, \mathrm{O}$ and $\mathrm{T}$.

Several trustworthy and reliable sources such as research articles, journals, newspapers, magazines, and search engines have been required for SWOT analyses (Sindhu et al., 2017). In this study, the factors for strengths, weaknesses, opportunities and threats for the SWOT analysis were conducted through a literature review, including policy documents, planning documents, action plans, reports, newspapers, articles, journals, books, etc. As explained earlier, Nanjing is used as an example in this study. In order to understand the development of the SNC better, all the materials reviewed are related to Nanjing. The purpose of this research is to evaluate the influencing factors for developing sustainable smart cities in China and prioritize them. Therefore, these influencing factors should be identified as independently as 


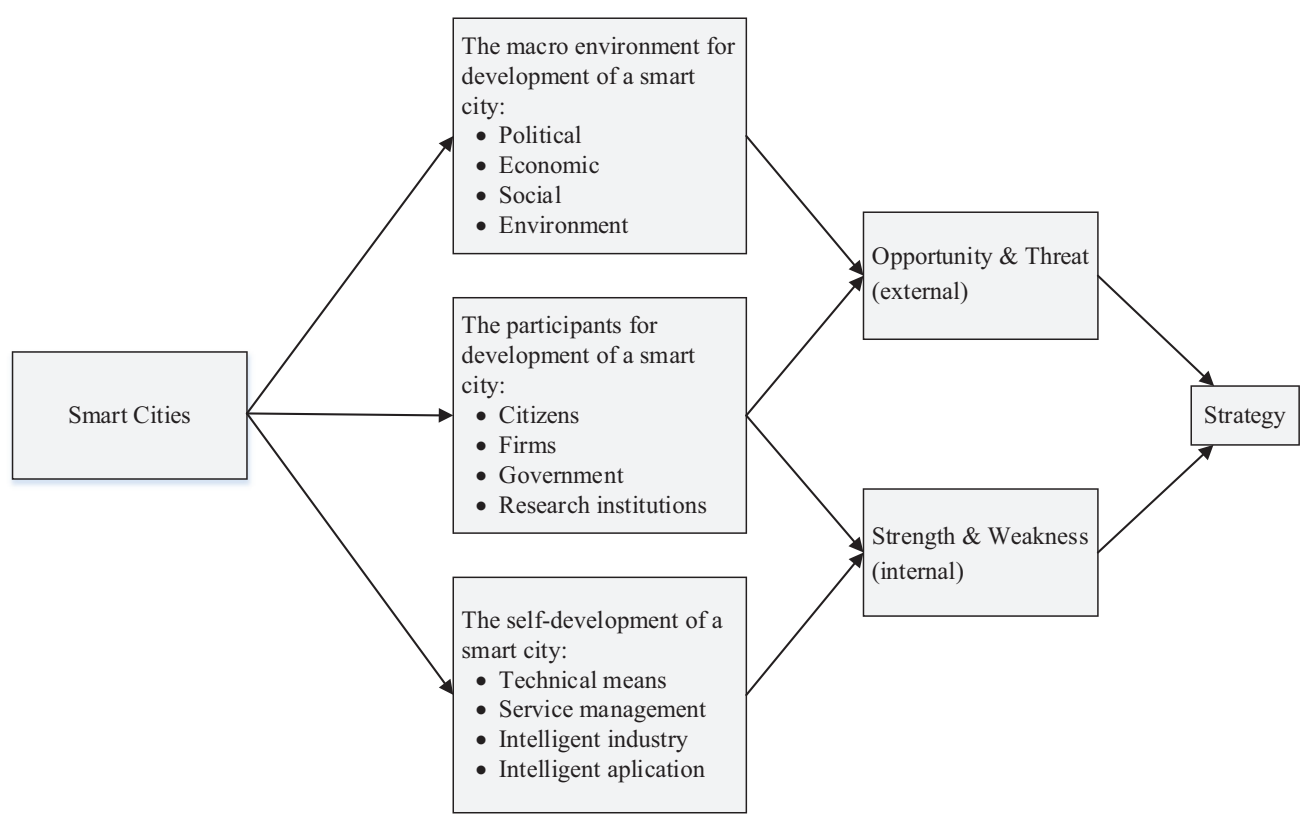

Figure 4. The path to identify SWOT factors

possible. When identifying factors, this research tries to ensure that they are independent of each other through defining different positive elements generated by the interaction between external environment and stakeholders as opportunities and different negative elements as threats and defining different positive elements generated by the interaction between internal conditions and stakeholders as strengths and different negative elements as weaknesses. Detailed identification and explanation are in the following sections.

\subsection{Strengths}

The development of intellectual technology is now growing quickly. From the perspective of technological development, smart city development requires the realization of comprehensive perception, ubiquitous interconnection, pervasive computing and integrated application through the application of NGIT. Therefore, in terms of smart city development, intellectual technology is its own advantage rather than external. Nanjing is one of the leading cities in China considering the informatization level, according to "Evaluation Report on the Level of Informatization Development in China" (Qin \& Luo, 2014) and the "Jiangsu Province informatization development report" (Jiangsu Provincial Government, 2015).

Strong support from local governments is the most important strength to facilitate smart cities development. Accordingly, the People's Government of Nanjing (NPG) have issued a number of policies to strongly and effectively promote the development of SNC, such as "The 12th five-year plan of smart city development in Nanjing" (NPG, 2011) and "The 13th five-year plan of smart city development in Nanjing” (NPG, 2017).
There are greatly increasing needs for intelligent applications in Nanjing, which can also be viewed as an important strength for developing SNC. According to "Investments in Nanjing", a series of intellectual products will undoubtedly become the components of intelligent life services to enhance the convenience of life for people with large investments in the intelligence industry in Nanjing (Nanjing Investment Promotion Center [NIPC], 2017). Moreover, in Nanjing, many new urban development projects, including Jiangbei New District, Airport New District, and many old city renewal projects, will bring more demands for intelligent applications.

Long-term good learning and innovative environments also provide sustainable strength for developing SNC. Nanjing is a city with many universities and research institutions, ranking No. 3 in China. Moreover, Nanjing built the Kylin Technology Innovation Park in 2015, and signed major projects, which effectively gathered a large number of specialized high-quality talents together, and laid the foundations for the promotion of innovation ability and the rapid development of intelligent technology in Nanjing.

\subsection{Weaknesses}

The development of smart cities requires huge investments (Söderström et al., 2014). In China, local governments are major participants in supporting smart city projects. However, local governments are unable to gather a large amount of funds in a short time due to the financial resources being mainly concentrated in central government (Jiang et al., 2014). Therefore, the financial resources available to NPG are insufficient to achieve all the smart projects needed. 
The security of information and networks is a critical weakness when developing smart cites. The development of Nanjing cloud platform gathers information to improve rates of resource sharing and resource utilization. However, at the same time, cloud technology, smart devices and agents, broadband networks, opening government data, and Web-based applications and e-Services, also bring huge risks to information security (Söderström et al., 2014). An enormous amount of information can be revealed and misused, which could pose a significant threat to countries, companies and personal privacy (Modi et al., 2013).

The difficulties in dealing with intellectual property are becoming ever greater due to the increasing complexity of people's requirements, which would lead to the realization of complicated functions. Although the usage of intellectual products has brought great convenience to people and made a huge contribution to products' values, it has also created new challenges and negative impacts, such as the use of smart meters in smart grids (Broman Toft et al., 2014).

Furthermore, an imperfect evaluation system has hindered the development of SNC. Evaluation is a key step in developing smart cities during the process of strategy definition, implementation, evaluation, and performance measurement for smart cities. Essentially, during the development of SNC, it lacked a clear long-term vision, which resulted in the local government finding it difficult to identify the smartness level of Nanjing (Wang \& Zheng, 2013). NPG should create a long-term academic, cultural, business vision for SNC.

\subsection{Opportunities}

There is an urgent need to adjust the structure of traditional industry. It also brings great new opportunities for high-technology industries and a lot of Small and Medium Enterprises, mainly working in energy, the environment or the NGIT industry. For example, the study results of the IBM China Institute of Business Value indicate that China has spent 30 billion CNY on the infrastructure for "smart health", which will offer nearly 160000 job positions directly and indirectly, most of which are knowledge-based jobs for college students (Gu et al., 2013).

Urban disease is an important problem existing in social management and public services and is caused by the imbalance between a rising population and urban resources (Marceau, 2008). Signs of urban disease have emerged in Nanjing, such as environmental degradation, traffic jams, overpopulation, etc. The traditional technologies and public management methods fail to resolve these problems, which are needed for developing SNC to strengthen urban public services and infrastructure technically, and to enhance the utilization of urban resources (Zhao et al., 2013). Therefore, the urgency of solving urban diseases in Nanjing provides great opportunities for developing SNC.

The demand to strengthen people's lives are the ultimate objectives to facilitate SNC. Smart cities development has been used as a strategy for increasing the quality of urban life (Dameri \& Cocchia, 2013). With economic, society-sustainable development, people begin to pay more attention to travel, security, education and other social services. According to "The 13th five-year plan of smart city development in Nanjing”, SNC emphasizes that it is "people-oriented" and concentrates on enhancing the citizens' life-quality and pursing the all-round development of society (NPG, 2017).

Furthermore, the demands for improving the level of public management and the ability to make decisions, brings the government new opportunities for developing SNC. Society development has placed higher demands on public management, which needs the government to coordinate the development of various fields in a timely manner (Chourabi et al., 2012). By developing SNC, it should be able to use intelligent information technology to understand, analyze and integrate various information into the city's operation system, thereby making intelligent responses, judgments, decisions and actions to meet demands and offer management in all aspects of the city in a timely manner (Kernaghan, 2014).

\subsection{Threats}

There are no clear objectives and precise identifications of requirements for different stakeholders in a smart city, which should be the most important threat for developing SNC. NPG lacks a standard definition of SNC to define its strategic vision and to establish a comprehensive framework that links all the projects and plans. Therefore, the smart city goals system cannot be built efficiently to present the features of Nanjing because the perception of SNC and its comprehensive framework are still unclear.

The political and legal system is inadequate for developing SNC. Therefore, it is difficult to put policies into practice. Policies issued by governments are important institutional resources for the evolution and expansion of an industry (Mladen \& Vanja, 2006). NPG has put forward the planning outline for developing SNC in 2009. However, the policies and corresponding measures related to SNC are still not perfect. In fact, the concept of Smart Cities in China has been mainly policy-driven. In this case, the impacts of policies on the development of smart cities should be highly addressed. Moreover, the practical application of related policies should also be very important, which can reflect the effects of policies (Scott, 2008).

A lack of relevant professionals in related fields has had a strongly negative impact on the sustainability of SNC. SNC development actually requires much intellectual capital investment along with the relevant professionals. Although there are many talents in Nanjing, the relevant professionals who can meet the needs of SNC development are few. The shortage of skilled and trained personnel has been identified as a critical barrier to facilitating the projects for smart cities in Europe (Mosannenzadeh et al., 2017). Similar to Europe, the advanced talents are deficient with the development of NGIT in such a short time, which will inevitably negatively affect SNC development. 
A shortage of effective communication among different departments of local government is also a significant threat factor for the SNC. A smart city, as an integrative framework, has urgent requirements for institutional mechanisms, whereby city should integrate all key infrastructure conditions, including bridges, seaports, rails, tunnels, airports, water, power, communications, roads, and even major buildings (Hall et al., 2000). The IoT and cloud computing development center in Nanjing have provided a good platform for social coordination governance. However, much of the information is relatively isolated from the rest and not open to other governmental departments, which are bottlenecks for data mining, applications, and utilization of data.

\subsection{SWOT factors generation for SNC}

To sum up, the initial list of SWOT factors for developing SNC is conducted. Then, the 21 experts detailed in Section 1.1 were interviewed face-to-face to discuss the rationality and independence of the identified factors, and to make corrections to propose the final list. Since there is not much difference between the initial list and the final list, this paper shows the final list directly (Figure 5).

\section{AHP-SWOT analysis}

According to the questionnaire data and Equation (3), shown in Section 1.2, the importance of the objectives is calculated as follows:

$$
w_{s}=0.28 ; w_{w}=0.22 ; w_{o}=0.27 ; w_{T}=0.23 \text {. }
$$

For the local importance of factors, this paper will show an example of the calculations by using the data from one expert in the survey (Table A1 in Appendix). According to Equation (6), it can be shown that the weight for each factor of the $S$ matrix about this expert is as follows:

$$
w_{S 1}=0.289, w_{S 2}=0.432, w_{S 3}=0.112, w_{S 4}=0.167 \text {. }
$$

Based on Equation (7), the value of $\lambda_{\max }$ for matrix $S$ is 4.187 .

In matrix $S$, the value of $C R$ is 0.069 , which is less than 0.1 , meaning that the calculation results in the local importance in group $S$ being acceptable. Thus, the results of the local importance in group $\mathrm{W}, \mathrm{O}$ and $\mathrm{T}$ also can be achieved by the same equations as those shown in Eqs. (6)-(9) (Table A3-A5 in Appendix).

According to Equation (10), the intensities for different SWOT groups can be obtained (Table A2-A5 in Appendix). The strategic value $V$ can be achieved from one

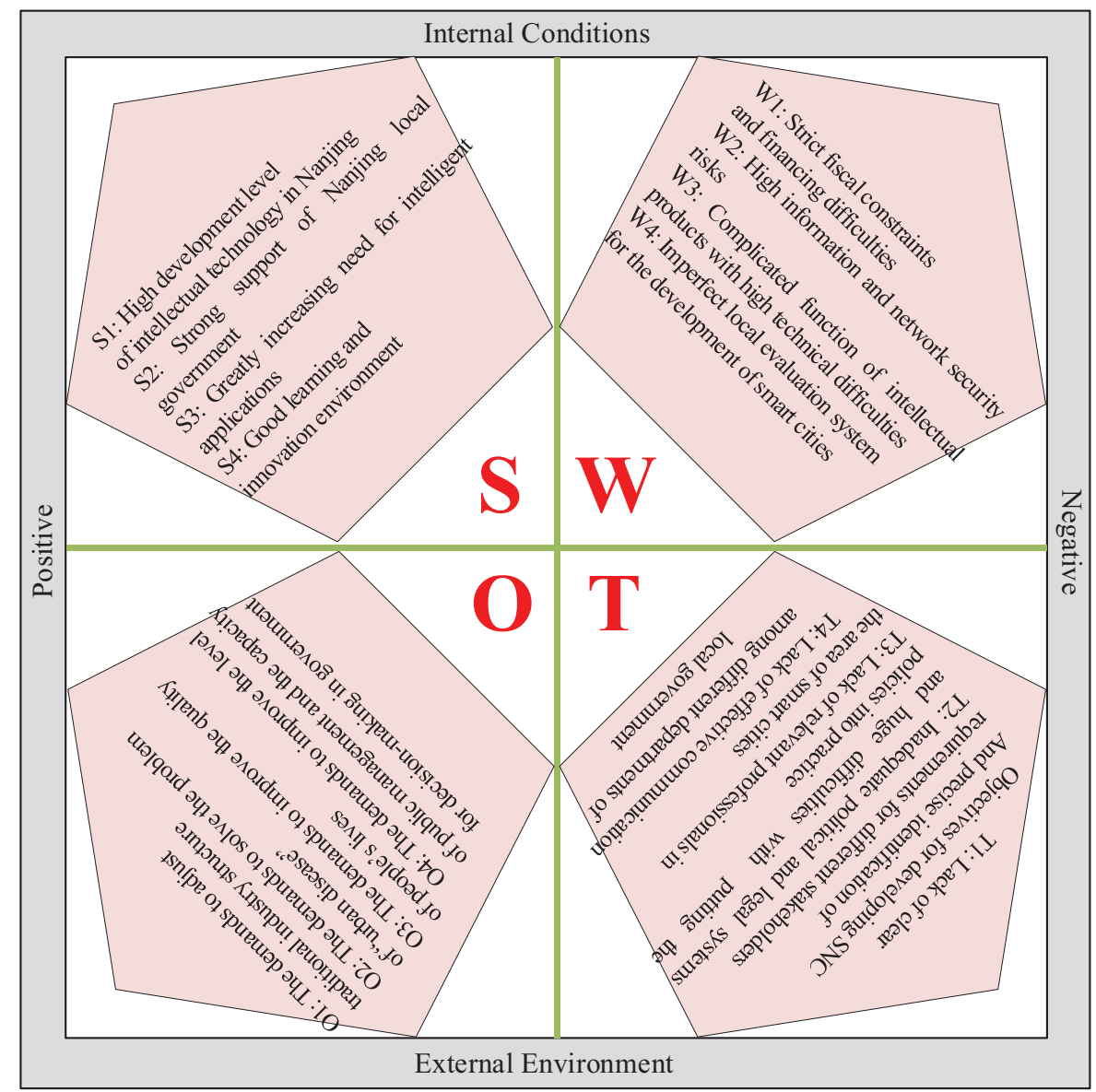

Figure 5. The SWOT factors 
questionnaire from Equation (4). According to Equation (11), the value of $V$ is 0.253 , greater than 0 , which means there are large strengths to facilitate the development of SNC and the positive strategies should be adopted. However, this result comes from one expert. All the experts' data will be used to make further analysis for achieving reasonable strategies. Then, the mean value (Table A6 in Appendix) and the intensities of the SWOT factors for all 21 experts are obtained (Table 4). The final groups' intensities and the final strategic value are shown in Table 4.

The value of the final strategy, based on the data from all respondents, is $V_{F}=0.174$, which indicates that the development of SNC has more positive effects than negative ones. The value of $V_{F}$ is small, which shows that hindering effects to facilitate SNC are still large. Table $4 \mathrm{dem}$ onstrates the priorities of strengths and opportunities to develop SNC are not inconsiderable, compared with the weaknesses and threats. However, the priorities of smart cities would become more obvious when more and more advanced technologies are being put into use and related policies can be issued.

The final factor intensities of different objectives have been obtained, as presented in Figure 6. For the positive effects from internal strengths and external opportunities, S1 (0.301), O1 (0.219), S4 (0.180) and O4 (0.148) are strong facilitating factors for the development of SNC, because of the intelligent, clean and green methods for urban development being used, as well as the highly effective energy consumption. Thus smart cities should be the best choice for urban development, which can help cities improve their competence and provide huge chances to move forward. Additionally, for the negative effects from internal weaknesses and external threats, W1 (-0.140), T1 $(-0.154)$, and $\mathrm{T} 4(-0.141)$ are critical hindering factors, which indicate that financing difficulties and inadequate political and legal systems are critical problems.

Table 4. Final group intensities and strategy values in SNC (all experts)

\begin{tabular}{|c|c|c|c|c|c|c|}
\hline Objectives & $\begin{array}{l}\text { Weights of } \\
\text { objectives }\end{array}$ & Factors & $\begin{array}{c}\text { Mean factor } \\
\text { intensities within } \\
\text { groups }\end{array}$ & $\begin{array}{c}\text { Final factor } \\
\text { intensities in all } \\
\text { groups }\end{array}$ & $\begin{array}{c}\text { Final group } \\
\text { intensities for all } \\
\text { experts }\end{array}$ & $\begin{array}{c}\text { Final strategy } \\
\text { value }\end{array}$ \\
\hline \multirow[t]{4}{*}{ S } & \multirow[t]{4}{*}{0.28} & S1 & 1.076 & 0.301 & \multirow[t]{4}{*}{0.217} & \multirow[t]{16}{*}{0.174} \\
\hline & & S2 & 0.561 & 0.157 & & \\
\hline & & S3 & 0.491 & 0.137 & & \\
\hline & & S4 & 0.643 & 0.180 & & \\
\hline \multirow[t]{4}{*}{ W } & \multirow[t]{4}{*}{0.22} & W1 & -0.637 & -0.140 & \multirow[t]{4}{*}{-0.098} & \\
\hline & & W2 & -0.359 & -0.079 & & \\
\hline & & W3 & -0.480 & -0.106 & & \\
\hline & & W4 & -0.557 & -0.123 & & \\
\hline \multirow[t]{4}{*}{$\mathrm{O}$} & \multirow[t]{4}{*}{0.27} & $\mathrm{O} 1$ & 0.810 & 0.219 & \multirow[t]{4}{*}{0.170} & \\
\hline & & $\mathrm{O} 2$ & 0.545 & 0.147 & & \\
\hline & & $\mathrm{O} 3$ & 0.432 & 0.117 & & \\
\hline & & $\mathrm{O} 4$ & 0.549 & 0.148 & & \\
\hline \multirow[t]{4}{*}{$\mathrm{T}$} & \multirow[t]{4}{*}{0.23} & T1 & -0.669 & -0.154 & \multirow[t]{4}{*}{-0.116} & \\
\hline & & $\mathrm{T} 2$ & -0.557 & -0.128 & & \\
\hline & & $\mathrm{T} 3$ & -0.345 & -0.079 & & \\
\hline & & $\mathrm{T} 4$ & -0.614 & -0.141 & & \\
\hline
\end{tabular}

\begin{tabular}{|c|c|c|}
\hline $\begin{array}{c}\text { Strategic } \\
\text { Options }\end{array}$ & Internal Strengths (S) & Internal Weaknesses (W) \\
\hline $\begin{array}{c}\text { External } \\
\text { Opportunities } \\
\text { (O) }\end{array}$ & $\begin{array}{l}\quad \text { SO Strategies } \\
\mathrm{SO}_{1} \text {-Making full use of different kinds of } \\
\text { new technologies }(\mathrm{S} 1 / \mathrm{S} 2 / \mathrm{S} 3 / \mathrm{S} 4-\mathrm{O} 1 / \mathrm{O} 2 / \\
\mathrm{O} 3) \\
\mathrm{SO}_{2} \text {-Facilitating the application of } \mathrm{Big} \\
\text { Data }(\mathrm{S} 1 / \mathrm{S} 2 / \mathrm{S} 3 / \mathrm{S} 4-\mathrm{O} 4)\end{array}$ & $\begin{array}{l}\text { WO Strategies } \\
\mathrm{WO}_{1} \text {-Adopting Public-Private Partnership (PPP) mode (O1/O3/O4-W1) } \\
\mathrm{WO}_{2} \text {-Building a Cyber Security Regime (O1/O4-W2) } \\
\mathrm{WO}_{3} \text {-Promoting the innovation of an NGIT }(\mathrm{O} 1 / \mathrm{O} 2 / \mathrm{O} 3 / \mathrm{O} 4-\mathrm{W} 3) \\
\mathrm{WO}_{4} \text {-Establishing SNC evaluation system }(\mathrm{O} 1 / \mathrm{O} 2 / \mathrm{O} 3 / \mathrm{O} 4-\mathrm{W} 4)\end{array}$ \\
\hline $\begin{array}{c}\text { External } \\
\text { Threats } \\
\text { (T) }\end{array}$ & $\begin{array}{l}\quad \text { ST Strategies } \\
\qquad \mathrm{ST}_{1} \text {-Setting clear objectives and } \\
\text { strengthening political and legal system } \\
\text { for developing } \mathrm{SNC}(\mathrm{S} 1 / \mathrm{S} 2 / \mathrm{S} 3 / \mathrm{S} 4-\mathrm{T} 1 / \mathrm{T} 2 / \\
\mathrm{T} 4) \\
\mathrm{ST}_{2} \text {-Establishing smart city knowledge } \\
\text { transfer platforms }(\mathrm{S} 1-\mathrm{T} 3)\end{array}$ & $\begin{array}{l}\text { WT Strategies } \\
\mathrm{WT}_{1} \text {-Developing a comprehensive and sustainable implementation } \\
\text { system for SNC }(\mathrm{W} 1 / \mathrm{W} 2 / \mathrm{W} 3 / \mathrm{W} 4-\mathrm{T} 1 / \mathrm{T} 2) \\
\mathrm{WT}_{2} \text {-Improving the attractiveness of SNC }(\mathrm{W} 1 / \mathrm{W} 2 / \mathrm{W} 3 / \mathrm{W} 4-\mathrm{T} 3 / \mathrm{T} 4)\end{array}$ \\
\hline
\end{tabular}

Figure 6. The intensities for different SWOT groups 


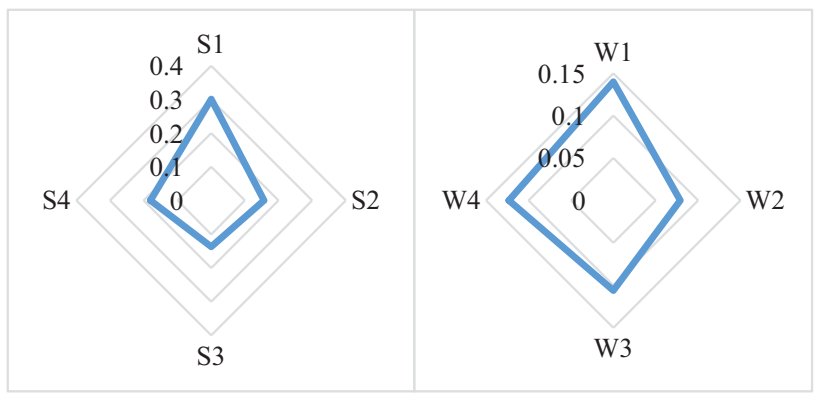

(a) Intensity of strength factor

(b) Intensity of weakness factor

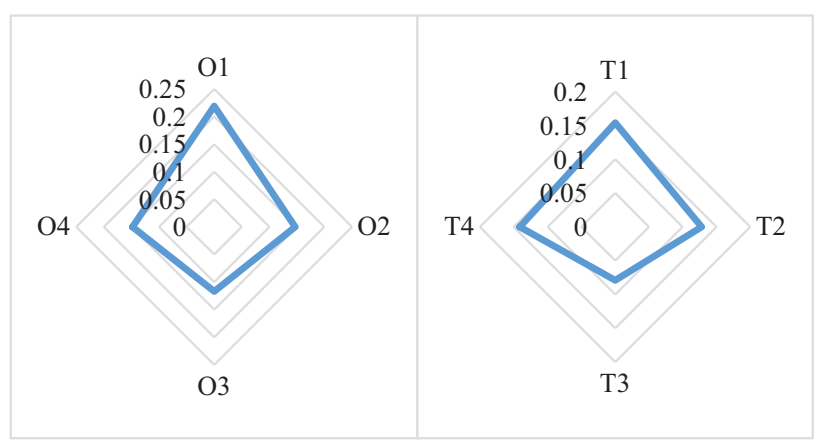

(c) Intensity of opportunity factor

(d) Intensity of threat factor

Figure 7. Final intensities for SWOT groups

The final intensities of SWOT groups from small to large are weakness (0.098), threat (0.116), opportunity (0.17), and strength (0.217), as presented in Figure 7. Therefore, the advantages for developing SNC are obvious. The development of intelligent technology, represented by the IoT and cloud computing, has advantages compared with traditional methods of urban development, which would contribute to the adoption of cleaner technologies and improve environmental performance. The opportunities to develop SNC can be obtained from the perspectives of demands for adjusting traditional industry structures, improving the level of public management, and the capacity to improve decision-making for governments, which show that the development of SNC is imminent. However, the intensity of threat groups comes near to that of opportunity groups, which indicates that the opportunities and challenges for developing SNC are coexisting. Providing clear strategy objectives, precise identifications of requirements, adequate political and legal systems and effective communication, related professional training, and eliminating the difficulties of putting the policies into practice, should be further improved upon before developing SNC. The negative impacts of the weakness group are minimal, which indicates that negative impacts are less important than the attractiveness of developing SNC, when facing enormous opportunities, whilst having their own strengths.

\section{Formulating strategies for SNC}

Therefore, active strategies for developing SNC can be proposed. First, based on this research, NPG should actively and aggressively develop SNC and address all the positive factors. Aggressive strategies, focusing on strengths and opportunities, are more inclined to become defensive options for developing SNC, which means the weaknesses and threats identified as presented before should be minimized when selecting strategy options. Therefore, three major strategies can be further proposed to meet future challenges and promote the sustainable development of SNC. The research findings can not only help the NPG explore an effective approach to facilitating the evolution and expansion of a smart city, but also provide guidance for other cities.

\subsection{Strategy formulation for SNC}

According to the quantitative calculation results of AHPSWOT above, logical SWOT combinations can be identified, including SO strategies, ST strategies, WO strategies, and WT strategies through cross analysis (Figure 8).

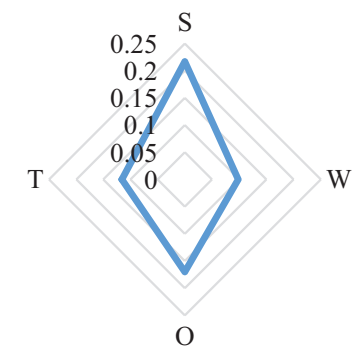

Figure 8. The application of SWOT matrix for SNC

SO strategies focus on utilizing the opportunities from external environments by using internal strengths.

- $\mathrm{SO}_{1}$ - Making full use of different kinds of new technologies (S1/S2/S3/S4-O1/O2/O3): NPG should seize the advantages of SNC and grasp the present opportunities. In this case, more and cleaner technologies such as ride-hailing services and bicycle sharing should be developed to meet the increasing requirements for SNC, focusing on the use of technology to produce digitalized services and improve efficiency in the city.

- $\mathrm{SO}_{2}$ - Facilitating the application of Big Data (S1/ S2/S3/S4-O4) (Sharifi, 2019): NPG should strengthen the application of Credit Big Data and promote the construction of "Integrity of Nanjing" platform (NPG, 2018). Meanwhile, it is necessary to establish and improve the Big Data Platform for Business Invitation, which can promote the success of major activities and improve the effectiveness of business invitation (NPG, 2019).

WO strategies focus on reducing internal weaknesses by using opportunities from the external environment.

- WO - Adopting Public-Private Partnership (PPP) mode (O1/O3/O4-W1): NPG should issue guidance to absorb the private sector into SNC development by using a PPP mode, because a number of relevant policies on PPP have been introduced by central government, which can solve the problem of financing difficulties. The objectives of the PPP mode in China 
are not only to resolve the problems related to fiscal constraints and financing difficulties, but also to enhance the quality of public services (Yang et al., 2017).

- $\mathrm{WO}_{2}$ - Building a Cyber Security Regime (O1/O4W2): The risks of information and network security have a very close relationship with industry, people's lives, and urban management. Therefore, NPG can establish a Cyber Security Regime to reduce risks for sustainable development of SNC (Parasol, 2017).

- $\mathrm{WO}_{3}$ - Promoting the innovation of an NGIT (O1/ $\mathrm{O} 2 / \mathrm{O} 3 / \mathrm{O} 4-\mathrm{W} 3)$ : The key technology is the product of technology innovation and industrial development, which can determine the development level of a smart city (Parasol, 2017). NPG should vigorously promote the innovation of an NGIT in the areas of product informatization, energy conservation, emission reduction, security production, which can strengthen enterprise management and intelligent development, as well as reduce environmental pollution.

- $\mathrm{WO}_{4}-$ Establishing SNC evaluation system (O1/O2/ O3/O4-W4): NPG should carefully design the local evaluation system on the sustainable development of SNC. Facing the new external opportunities, the evaluation system should contain the priorities and weaknesses of industrial structure, urban management, people's lives, public management, and decision-making by governments, which can provide guidance for developing SNC (Gu et al., 2013).

ST strategies focus on minimizing the threats from external environments by using internal strengths.

- ST $T_{1}$ Setting clear objectives and strengthening political and legal system for developing SNC (S1/S2/S3/S4T1/T2/T4): It is useful to set clear objectives related to intellectual technology, intelligent application, as well as learning and innovation environments, which would provide useful guidelines for NPG to develop smart cities. Meanwhile, the government's political and legal system should be strengthened, including sufficient political papers and legal provisions.

- ST $T_{2}$ - Establishing smart city knowledge transfer platforms (S1-T3): Carrillo et al. (2006) indicated that the establishment of knowledge transfer platforms is crucial for smart cities. Nanjing intellectual technology level is higher than that of most of cities because many universities and high technology enterprises are located in Nanjing. It is useful to train relevant professionals in the field of smart cities to realize knowledge transfer for NPG by using the existing human resources priorities, such as management and technical professionals.

WT strategies focus on reducing the internal weaknesses for avoiding the threats from external environment.

- $W T_{1}$ - Developing a comprehensive and sustainable implementation system for SNC (W1/W2/W3/ W4-T1/T2): NPG should try its best to eliminate the shortcomings for developing SNC, solving the financing difficulties, information security risks and other issues. Simultaneously, different departments of government should be communicated with effectively, using intellectual technologies and intelligent application with the support of local authorities.

- WT $T_{2}$ - Improving the attractiveness of SNC (W1/W2/ W3/W4-T3/T4): SNC consists of intelligent transportation, smart governance, intelligent medical, and other intelligent projects. It should be built by NPG, which can boost the sharing of information resources and the collaboration of business among departments at different levels. Meanwhile, NPG should adhere to taking the best of the Internet thinking for innovation, pay attention to meeting different kinds of requirements, individualize the needs of people and promote the participation of people in urban transformation, which can attract a large number of related professionals.

\subsection{Policy suggestion to develop SNC}

Although SO, WO, ST, and WT strategies have been proposed, there are many overlapping elements. Therefore, based on the quantitative calculation results, three primary overall suggestions (intelligent clusters, governance ecosystems, and integrated services) can be further proposed, as below, to deal with future challenges and promote the sustainable development of SNC (Table 5).

According to $\mathrm{SO}_{1}, \mathrm{WO}_{3}$, and $\mathrm{ST}_{2}$, strengthening the intelligent cluster should be an important suggestion to develop SNC from the perspective of technology development. According to the futures of development of high technologies in Nanjing, NPG should focus on the development of Big Data (Sharifi, 2019), Artificial Intelligence, Next Generation Network, IoT, telecommunication-cable television-computer networks convergence, new flat-panel display, high performance integrated circuit and cloud computing, as well as facilitating the innovation of these technologies by 2030 (NIPC, 2017; NPG, 2019). Innovation is indispensable to the sustainable development of

Table 5. Policy suggestions

\begin{tabular}{|l|l|l|}
\hline \multicolumn{1}{|c|}{ Logical SWOT combinations } & \multicolumn{1}{c|}{ Driven } & \multicolumn{1}{c|}{ Primary overall suggestions } \\
\hline $\mathrm{SO}_{1}, \mathrm{WO}_{3}, \mathrm{ST}_{2}$ & Technology & Intelligent clusters \\
\hline $\mathrm{WO}_{1}, \mathrm{ST}_{1}, \mathrm{WO}_{4}$ & Institutional environment & Governance ecosystems \\
\hline $\mathrm{SO}_{2}, \mathrm{WO}_{2}, \mathrm{WT}_{1}, \mathrm{WT}_{2}$, & The demands of people & Integrated services \\
\hline
\end{tabular}


SNC (Sharifi, 2019). For the innovative subjects, a gradient development promotion mechanism can be adopted for facilitating the development of high-technology enterprises by NPG. For the innovative environment, NPG should accelerate the construction of Major Scientific and Technological Innovation Platforms, such as Fifth Generation (5G) Mobile Communication and Future Network Experiment Facility (NPG, 2018). Meanwhile, the development of a number of new research institutions such as Nanjing Intelligent Manufacturing Research Institute should be promoted. Furthermore, NPG should integrate these technologies with the real economy, and form a modern industrial system dominated by strategic emerging industries, such as Liquid Crystal Display Industry, Software and Information Service Industry, Modern Communication Industry, Satellite Application Industry, and Integrate Circuit Industry, which is in line with the development policies proposed by "Investments in Nanjing" (NIPC, 2017).

According to $\mathrm{WO}_{1}, \mathrm{ST}_{1}$, and $\mathrm{WO}_{4}$, a governance ecosystem should be adopted to take full use of Nanjing's advantages to promote the sustainable development of SNC. The key to a governance ecosystem is to optimize the relationship between funds, resources, and technologies through a governance structure, including NPG, enterprises, the community, and the market. The collaborations between the public and private sector investment for SNC development should be encouraged, which would cope with the financial problem (NPG, 2017). PPPs can be adopted to participate in high-technological innovations and strategic emerging industries development. Universities and R\&D institutions in Nanjing can provide technological innovations, conceptual development innovations, management mechanism innovations, operation mode innovations, capital operation innovations, etc. NPG should promote the transformation of Jiangning, Xianlin and Jiangbei university towns into innovation towns and promote the development of the Yangtze Ecological Civilization Innovation Center, so as to accelerate the creation of a number of major and original achievements (NPG, 2019).
The efficient cooperation between network communication and Zijinshan Security Laboratory should be further promoted, which can deal with the high risk of information and communication security (NPG, 2019). Moreover, a coordination mechanism should be included to guide communication and action among multiple departments of NGP (Sodiq et al., 2019). In the context of the governance ecosystem, policy support, enough investments, feasible intelligent solutions, and enough professionals should be provided, which can facilitate the sustainable development of SNC. These fit well with the local government policies "Investments in Nanjing" (NIPC, 2017) and "2019 Nanjing People's Government work report" (NPG, 2019).

According to $\mathrm{SO}_{2}, \mathrm{WO}_{2}, \mathrm{WT}_{1}$, and $\mathrm{WT}_{2}$, further integrated services of SNC should be provided to facilitate the application of smart technologies and change the social and cultural environment of the city. The eventual development of SNC will give people in Nanjing a better service. The supply of goods and services can be further optimized to meet final demands and expand new market. Based on the support of high-technologies, the needs of various stakeholders should be discovered timely and accurately (Sharifi, 2019), such as culture and environment aspects, and then great efforts should be made to meet them, so that supply and demand can reach a balance. NPG should vigorously promote the "Internet + Government Service" and establish the Big Data Base of government service for SNC (NPG, 2019). Meanwhile, the opening of government data should be promoted to the society, so as to realize the share of information resources. Furthermore, NPG should comprehensively evaluate the level of public services in SNC, such as transportation, education, health, hospital, old-age care, etc., so as to improve the quality of life of the people through the healthy and sustainable development of SNC. These are in keeping with local government policies "The 13th five-year plan of smart city development in Nanjing" (NPG, 2017).

The policy suggestions can be viewed as a system as shown in Figure 9.

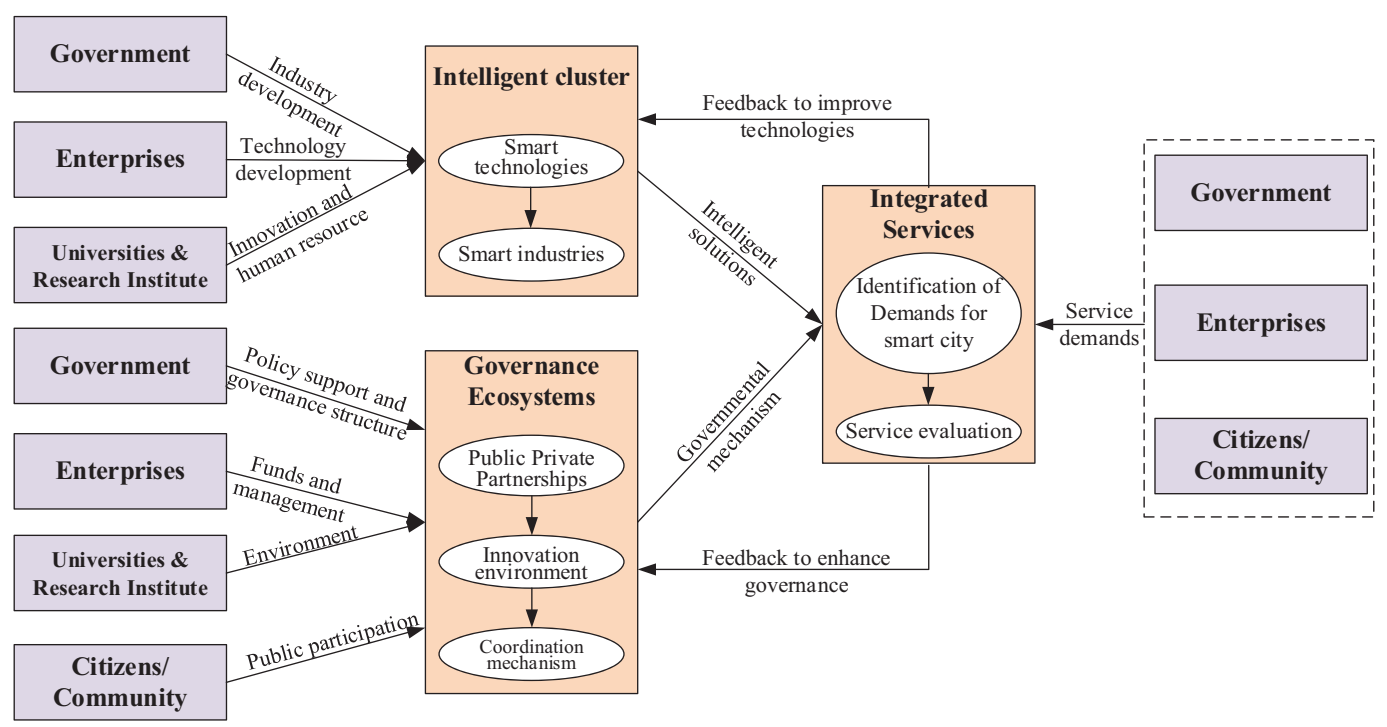

Figure 9. The policy suggestions to develop smart Nanjing 


\subsection{The implications for other cities}

First, the policy suggestions of intelligent clusters, governance ecosystems, and integrated services provide a hybrid strategic planning approach by integrating bottomup and top-down designs to develop SNC, which can be promoted for other cities to develop smart cities. From a bottom-up perspective, intelligent clusters focus on the development of high-technologies like Big Data and Artificial Intelligence. Technology-led urban systems have always been the traditional strategic principle for developing smart cities, which can drive the development of health, transportation, culture, education, and the environment (Mora et al., 2019). However, Vu and Hartley (2018) indicate that the emphasis on the "hardware" (e.g. technology) and "software" (e.g. requirements management) should be balanced. Therefore, different from prior studies, the proposed intelligent clusters should not only focus on the technology, but also consider integrating the high-technology with the real economy, and form a modern industrial system dominated by strategic emerging industries. A smart city is not a technology-only focused system, with large-scale NGIT devices and infrastructures (Mora et al., 2019). Thus, the proposed integrated services, including smart living and smart people, should be established to timely and accurately discover and meet the requirements of stakeholders from human, social, cultural, economic and environmental aspects with the support of high-technologies. The interaction between technologies and people can provide a proactive framework for developing a smart city from a bottom-up perspective, which still needs governance from a top-down perspective to avoid reduplication, resource waste, chaos and a lack of long-term vision (Mora et al., 2019). The governance ecosystem of a smart city is therefore designed to coordinate the relationships across funds, resources, technologies, people and institutions to realize smart people and smart living. A lack of effective governance is viewed as a hindrance for developing smart cities by Vu and Hartley (2018). Prior studies address the integration of different components (e.g. stakeholders, processes, technologies, data, etc.) in smart city governance (Ruhlandt, 2018). The proposed governance ecosystem provides an effective institutional approach and structure to bring multiple stakeholders together to promote smart services and smart utilization of resources. Considering the characteristic of Nanjing, the adoption of a PPP method and the role of universities and R\&D organizations are highly addressed. Therefore, different components in the proposed governance ecosystem can be connected through multiple kinds of flow (e.g. money, data, demands, and human resources, technologies, policies), which finally construct a multi-dimensional governance system. For other cities in the world, the combined method, integrating bottom-up and top-down designs to develop smart cities can be encouraged, because the technologies, people, and institutions cannot be ignored in any case. Meanwhile, the city's social and economic situation, as well as the level of related technologies, professionals, and resources should also be considered when formulating strategies to develop smart cities.

Another important contribution of this study is to establish a method of quantitative analysis to formulate the smart city development strategies. As shown in Table 6, different strategies may have different priorities, which can be calculated by using the proposed approach and cannot be reflected in prior studies. Based on the SWOT-AHP calculation results, a quantitative priority analysis can be obtained. According to Table 6, the strategic value of $\mathrm{SO}_{1}$ is 1.258 , which is an absolute advantage in the strategy of intelligent clusters. Therefore, making full use of different kinds of new technologies $\left(\mathrm{SO}_{1}\right)$ is the first strategic combination of the three in an intelligent cluster strategy, which should be undertaken for developing sustainable SNC. NPG should promote the construction of Innovation City, cultivate innovation subjects, enhance independent innovation ability, and construct the pattern of development and innovation. The sequence of strategic portfolio implementations is sorted by strategic value. Therefore, setting clear objectives and strengthening political and legal system for developing $S N C\left(S T_{1}\right)$ and facilitating the application of Big Data $\left(\mathrm{SO}_{2}\right)$ are the priorities of the Governance ecosystem and Integrated services, respectively. For the policy suggestions, the highest priority should be put into the Governance ecosystem, which means governance is

Table 6. The priorities of different strategies in developing SNC

\begin{tabular}{|l|l|l|l|l|l|l|}
\hline \multicolumn{1}{|c|}{ Strategy } & \multicolumn{1}{|c|}{ SO } & \multicolumn{2}{c|}{ WO } & \multicolumn{1}{c|}{ ST } & WT & $\begin{array}{c}\text { Total strategy } \\
\text { value }\end{array}$ \\
\hline $\begin{array}{l}\text { Intelligent } \\
\text { cluster }\end{array}$ & $\mathrm{SO}_{1}(1.258)$ & $\mathrm{WO}_{3}(0.737)$ & $\mathrm{ST}_{2}(0.38)$ & & 2.375 \\
\hline $\begin{array}{l}\text { Governance } \\
\text { ecosystem }\end{array}$ & & $\mathrm{WO}_{1}(0.624)$ & $\mathrm{WO}_{4}(0.754)$ & $\mathrm{ST}_{1}(1.198)$ & & 2.576 \\
\hline $\begin{array}{l}\text { Integrated } \\
\text { services }\end{array}$ & $\mathrm{SO}_{2}(0.923)$ & $\mathrm{WO}_{2}(0.446)$ & & $\mathrm{WT}_{1}(0.73)$ & $\mathrm{WT}_{2}(0.448)$ & 2.547 \\
\hline
\end{tabular}

Where, $\mathrm{SO}_{1}=\mathrm{S} 1+\mathrm{S} 2+\mathrm{S} 3+\mathrm{S} 4+\mathrm{O} 1+\mathrm{O} 2+\mathrm{O} 3=1.258 ; \mathrm{SO}_{2}=\mathrm{S} 1+\mathrm{S} 2+\mathrm{S} 3+\mathrm{S} 4+\mathrm{O} 4=0.923 ; \mathrm{WO}_{1}=\mathrm{O} 1+\mathrm{O} 3+\mathrm{O} 4+$ $\mathrm{W} 1=0.624 ; \mathrm{WO}_{2}=\mathrm{O} 1+\mathrm{O} 2+\mathrm{W} 2=0.446 ; \mathrm{WO}_{3}=\mathrm{O} 1+\mathrm{O} 2+\mathrm{O} 3+\mathrm{O} 4+\mathrm{W} 3=0.737 ; \mathrm{WO}_{4}=\mathrm{O} 1+\mathrm{O} 2+\mathrm{O} 3+\mathrm{O} 4+$ $\mathrm{W} 4=0.754 ; \mathrm{ST}_{1}=\mathrm{S} 1+\mathrm{S} 2+\mathrm{S} 3+\mathrm{S} 4+\mathrm{T} 1+\mathrm{T} 2+\mathrm{T} 4=1.198 ; \mathrm{ST}_{2}=\mathrm{S} 1+\mathrm{T} 3=0.38 ; \mathrm{WT}_{1}=\mathrm{W} 1+\mathrm{W} 2+\mathrm{W} 3+\mathrm{W} 4+$ $\mathrm{T} 1+\mathrm{T} 2=0.73 ; \mathrm{WT}_{1}=\mathrm{W} 1+\mathrm{W} 2+\mathrm{W} 3+\mathrm{W} 4+\mathrm{T} 3+\mathrm{T} 4=0.448$ 


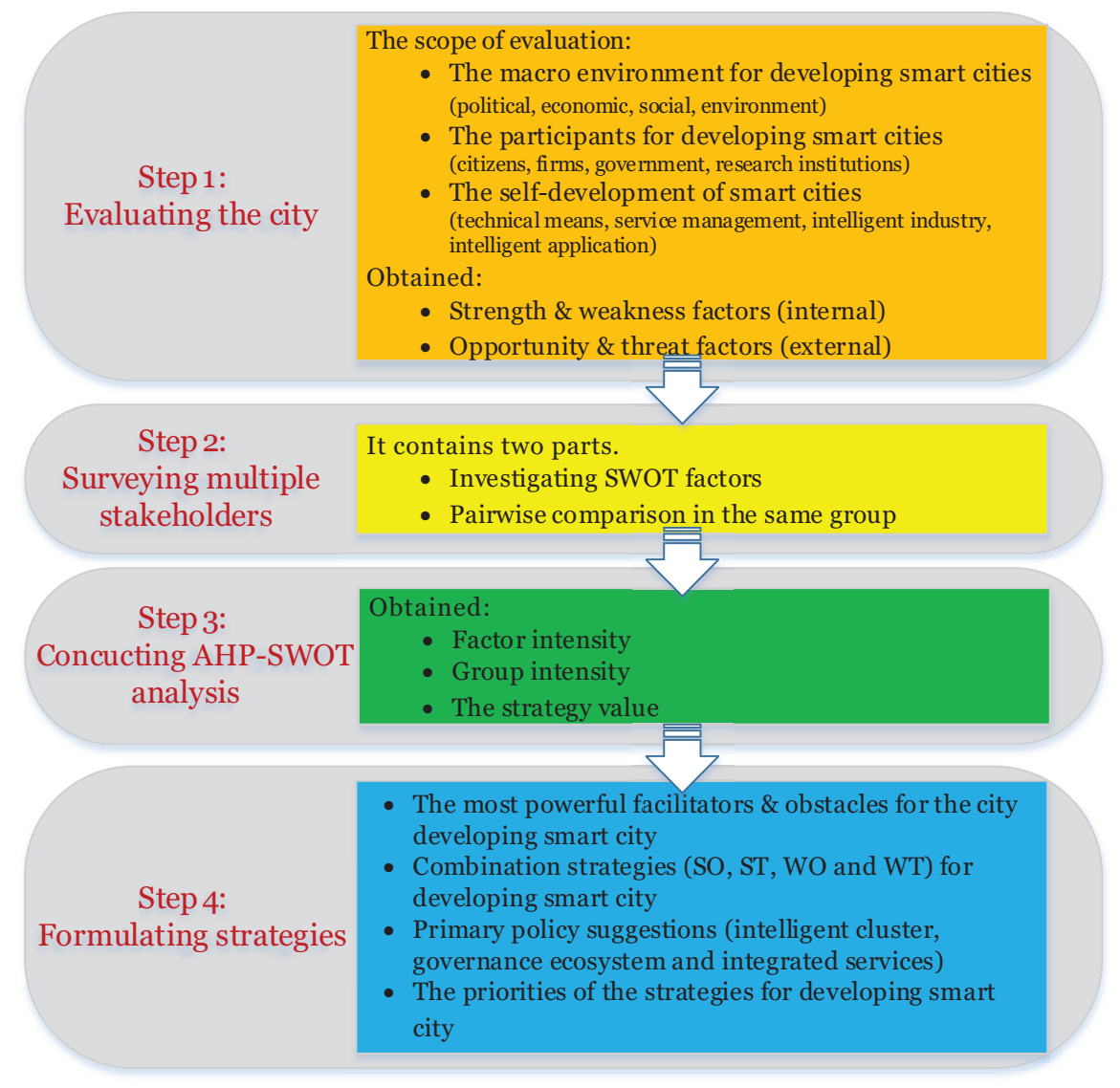

Figure 10. The roadmap for other cities developing strategies

the most important in the SNC development, focusing on the integration of different smart components in Nanjing. Integrated services are the second most important policy suggestion according to the results, which means precise identification of service demands and a reasonable evaluation system can be adopted to facilitate the development of SNC. Meanwhile, Intelligent clusters can provide a foundation for a Governance ecosystem and Integrated services.

For other cities, the proposed approach can be calibrated as Figure 10. The first step of the strategy formulation should focus on evaluating the status related to the smart city development for specific cities to identify different factors in the SWOT analysis. Then a similar survey and proposed AHP-SWOT analysis can be conducted. Finally, the strategies to develop smart cities can be raised according the results. In the future, more data will be collected to develop strategies for different cities to develop smart cities. The roadmap can be adopted for any city in the world.

\section{Conclusions}

Rapid urbanization has caused a series of "urban disease" in China. A smart city is regarded as an effective solution to deal with "urban disease" and promote sustainable urban development. There are many strategies for developing smart cities around the world and researchers have undertaken many studies on their design and implementation processes. However, many cities have unclear or similar strategies for developing sustainable smart cities. In order to realize the sustainable and healthy development of smart cities in China, this paper puts forward a strategy formulation thinking that comprehensively considers the combination of top-down and bottom-up.

Every city has different characteristics. Taking Nanjing as an example, this study identified the strength, weakness, opportunity and threat factors for developing SNC from the macro environment, participants and its self-development. As the factors and their intensities are scored by experts from governments, related industries, and research institutes, the strategies proposed are more acceptable to the public. Different from previous studies, this paper provides a quantitative path analysis for the strategic formulation of sustainable developments for smart cities by integrating SWOT and AHP methods. Based on the most powerful motivators and the strongest hindering factors, a proactive strategy has been put forward for developing SNC, including a couple of strategies. Moreover, intelligent clusters, governance ecosystems, and integrated services, which are primary suggestions, as well as their priorities were proposed to deal with future challenges in SNC development. 
The research results can not only help NPG explore an effective approach to promoting and developing a smart city, but also provide the guidance for other cities in China with similar characteristics (region, urban hierarchy, administrative category, policy support, population, Gross Domestic Production, colleges and universities, etc.) to develop smart cities. At the same time, the hybrid strategy planning approach proposed in this paper, which combines bottom-up and top-down designs, can also provide ideas for other cities in the world to develop smart cities. Furthermore, the proposed AHP-SWOT hybrid method establishes a quantitative analysis model to formulate smart city development policy suggestions, which also can be used as effective strategy planning tools to help other countries determine appropriate strategies in developing their own smart cities. Each city is different in its economy, resources, policies, environment, etc., this paper considered contextrelevance issues to help cities develop smart cities based on their own strengths and weaknesses. The proposed model of Industry-University-Research Collaboration can provide useful guidance for the development of smart cities.

Some limitations still exist. The questionnaire data are collected from local government, enterprises and research experts in Nanjing, reflecting the opinions of a specific city, meaning the policies may not apply to other cities. Meanwhile, the SWOT factors are relatively independent. Simultaneously, it is difficult to do the pairwise comparisons for the judgments, because the subjectivity is relatively strong, which may cause biases, although the selected experts have solid theoretical foundations, rich practical experience and strong professional backgrounds. Hence, the introduction of ANP and fuzzy methods could be adopted in future studies. Meanwhile, the focus of the SWOT analysis is on SNC. However, it can be partitioned into many sub-systems, from different perspectives. Thus, further research may be to conduct a national survey to collect extensive amounts of data and compare the opinions from different regions.

\section{Acknowledgements}

The authors gratefully acknowledge all survey participants and reviewers of the paper, and financial support from National Natural Science Foundation of China (NSFC71671042, 71472037); the Social Science Foundation of Jiangsu Province, China (13GLB005); the Fundamental Research Funds for the Central Universities; the Postgraduate Science and Innovation Foundation of Jiangsu Province (Grand No. KYLX_0206) for financially supporting this research.

\section{Funding}

This work was supported by the funding as follows: - <National Natural Science Foundation of China, NSFC > under Grant [71671042, and 71472037];

- <National Social Science Foundation of China $>$ under Grant [19CGL065];
- $<$ Social Science Foundation of Jiangsu Province, China> under Grant [13GLB005];

$-<$ Fundamental Research Funds for the Central Universities $>$;

- $<$ Postgraduate Science and Innovation Foundation of Jiangsu Province> under Grant [No. KYLX_0206].

\section{Author contributions}

Jingfeng Yuan and Hong Xie conceived the study and were responsible for the design and development of the data analysis. Hong Xie and Jingfeng Yuan wrote the first draft of the article. Dujuan Yang, Xiaer Xiahou, Mirosław J. Skibniewski, and Wei Huang were responsible for revise the work, add new ideas and adjust the logic of the article.

\section{Disclosure statement}

All authors declare that we do not have any competing financial, professional, or personal interests from other parties.

\section{References}

Ahvenniemi, H., Huovila, A., Pinto-Seppa, I., \& Airaksinen, M. (2017). What are the differences between sustainable and smart cities? Cities, 60(A), 234-245.

https://doi.org/10.1016/j.cities.2016.09.009

Angelidou, M. (2017). The role of smart city characteristics in the plans of fifteen cities. Journal of Urban Technology, 24(4), 3-28. https://doi.org/10.1080/10630732.2017.1348880

Bednarska-Olejniczak, D., Olejniczak, J., \& Svobodová, L. (2019). Towards a smart and sustainable city with the involvement of public participation - the case of Wroclaw. Sustainability, 11(2), 332. https://doi.org/10.3390/su11020332

Ben Letaifa, S. (2015). How to strategize smart cities: revealing the SMART model. Journal of Business Research, 68(7), 1414-1419. https://doi.org/10.1016/j.jbusres.2015.01.024

Bilbil, E. T. (2017). The operationalizing aspects of smart cities: the case of Turkey's smart strategies. Journal of the Knowledge Economy, 8, 1032-1048. https://doi.org/10.1007/s13132-016-0423-3

Broman Toft, M., Schuitema, G., \& Thøgersen, J. (2014). Responsible technology acceptance: model development and application to consumer acceptance of Smart Grid technology. Applied Energy, 134, 392-400.

https://doi.org/10.1016/j.apenergy.2014.08.048

Carrillo, P. M., Robinson, H. S., Anumba, C. J., \& Bouchlaghem, N. M. (2006). A knowledge transfer framework: the PFI context. Construction Management and Economics, 24(10), 1045-1056. https://doi.org/10.1080/01446190600799224

Chourabi, H., Gil-Garcia, J. R., Pardo, T. A., Nam, T., Mellouli, S., Scholl, H. J., Walker, S., \& Nahon, K. (2012). Understanding smart cities: an integrative framework. In IEEE, 2012 45th Hawaii International Conference on System Sciences (pp. 2289-2297). https://doi.org/10.1109/HICSS.2012.615

Dameri, R. P., \& Cocchia, A. (2013). Smart city and digital city: twenty years of terminology evolution. In X Conference of the Italian Chapter of AIS, ITAIS (pp. 1-8).

Ghimire, L. P., \& Kim, Y. (2018). An analysis on barriers to renewable energy development in the context of Nepal using AHP. Renewable Energy, 129(A), 446-456.

https://doi.org/10.1016/j.renene.2018.06.011 
Giest, S. (2017). Big data analytics for mitigating carbon emissions in smart cities: opportunities and challenges. European Planning Studies, 25(6), 941-957.

https://doi.org/10.1080/09654313.2017.1294149

Gu, S., Yang, J., \& Liu, J. (2013). Problems in the development of smart city in China and their solution. China Soft Science, 1, 6-12 (in Chinese).

Hall, R. E., Bowerman, B., Braverman, J., Taylor, J., Todosow, H., \& Von Wimmersperg, U. (2000). The vision of a smart city. Paper presented at the $2^{\text {nd }}$ International Life Extension Technology Workshop, Paris, France.

Information Research Center of Chinese Academy of Social Sciences. (2016). The sixth (2016) evaluation report on the development level of smart cities in China (in Chinese).

Jeon, Y. A., \& Kim, J. (2011). An application of SWOT-AHP to develop a strategic planning for a tourist destination. Paper presented at the 16th graduate students research conference. https://scholarworks.umass.edu/gradconf_hospitality/2011/ Poster/37/

Jiang, M., Wu, Y., Ding, Y., Xiong, G., \& Sun, C. (2014). Research on smart city system and the investment and operation mode of the project. E-Government, 12, 93-100 (in Chinese).

Jiangsu Provincial Government. (2015). Jiangsu Province informatization development report. http://www.jiangsu.gov.cn/ art/2015/12/19/art_33686_2313699.html

Kernaghan, K. (2014). Digital dilemmas: values, ethics and information technology. Canadian Public Administration, 57(2), 295-317. https://doi.org/10.1111/capa.12069

Kurttila, M., Pesonen, M., Kangas, J., \& Kajanus, M. (2000). Utilizing the analytic hierarchy process (AHP) in SWOT analysis - a hybrid method and its application to a forestcertification case. Forest Policy and Economics, 1(1), 41-52. https://doi.org/10.1016/S1389-9341(99)00004-0

Lee, J. H., Hancock, M. G., \& Hu, M. C. (2014). Towards an effective framework for building smart cities: lessons from Seoul and San Francisco. Technological Forecasting and Social Change, 89, 80-99. https://doi.org/10.1016/j.techfore.2013.08.033

Li, X., Li, H., Sun, B., \& Wang, F. (2018). Assessing information security risk for an evolving smart city based on fuzzy and grey FMEA. Journal of Intelligent \& Fuzzy Systems, 34(4), 2491-2501. https://doi.org/10.3233/JIFS-172097

Liu, Y. (2015). Improving the smart city quality of Nanjing. China Economic \& Trade Herald, 25, 43-44 (in Chinese). http://www. cnki.com.cn/Article/CJFDTOTAL-ZJMD201525025.htm

Luan, S., \& Li, Y. (2015). How to scientifically construct a smart city. In Z. J. Zhang, Z. J. M. Shen, J. L. Zhang, \& R. T. Zhang (Eds.), LISS 2014 Proceedings of 4th International Conference on Logistics, Informatics and Service Science (pp. 595-601). https://doi.org/10.1007/978-3-662-43871-8

Marceau, J. (2008). Innovation in the city and innovative cities. Innovation: Management, Policy \& Practice, 10(2), 136-145. https://doi.org/10.5172/impp.453.10.2-3.136

Matthews, J. R. (2004). Technology planning: preparing and updating a library technology plan. Libraries Unlimited.

Ministry of Housing and Urban-Rural Development (MOHURD). (2012). Temporary administrative measures for a smart city pilot in China. Indicator system for a smart city pilot in China. http://www.mohurd.gov.cn/wjfb/201212/ t20121204_212182.html

MOHURD. (2013a). Notice on the release of the first pilot list of smart cities in China. http://www.mohurd.gov.cn/ wjfb/201302/t20130204_212789.html
MOHURD. (2013b). Notice on the release of the 2013 pilot list of smart cities in China. http://www.mohurd.gov.cn/ wjfb/201308/t20130805_214634.html

MOHURD. (2014). Notice on the release of the 2014 pilot list of smart cities in China. http://www.mohurd.gov.cn/ wjfb/201408/t20140829_218853.html

Mladen, M., \& Vanja, S. (2006). Digital to intelligent local government transition framework. Paper presented at the MIPRO 2006 29th International Convention.

Modi, C., Patel, D., Borisaniya, B., Patel, A., \& Rajarajan, M. (2013). A survey on security issues and solutions at different layers of cloud computing. Journal of Supercomputing, 63(2), 561-592. https://doi.org/10.1007/s11227-012-0831-5

Mora, L., Deakin, M., \& Reid, A. (2019). Strategic principles for smart city development: a multiple case study analysis of European best practices. Technological Forecasting and Social Change, 142, 70-97. https://doi.org/10.1016/j.techfore.2018.07.035

Mosannenzadeh, F., Di Nucci, M. R., \& Vettorato, D. (2017). Identifying and prioritizing barriers to implementation of smart energy city projects in Europe: an empirical approach. Energy Policy, 105, 191-201. https://doi.org/10.1016/j.enpol.2017.02.007

Nanjing Investment Promotion Center (NIPC). (2017). Investments in Nanjing. http://invest.nanjing.gov.cn/whxznj/njys/cyjjys/

Nanjing People's Government (NPG). (2011). The 12th five-year plan of smart city development in Nanjing. https://www.baidu. com/link?url=0jVVYy7LKQG0S2-dYE-dBn5JVfTvPq8Pe6Bp9qRRww4XJaBN3Za-mc9F27a500iWYo-lKFdHyJo9B8BPU oDwp37c3WDZqrU6bNHt5I2aEa3\&wd=\&eqid=fc5f911900 2259a9000000065cfe04b4

NPG. (2017). The 13th five-year plan of smart city development in Nanjing. http://www.nanjing.gov.cn/zdgk/201810/ t20181022_573428.html

NPG. (2018). 2018 Nanjing People's Government work report. http://www.nanjing.gov.cn/zdgk/201902/t20190215_1404802. html

NPG. (2019). 2019 Nanjing People's Government work report. http:// www.nanjing.gov.cn/zdgk/201902/t20190228_1438487.html

National Bureau of Statistics. (2016). Statistic bulletin of national economy and social development in 2016. http://www.stats.gov. cn/tjsj/zxfb/201702/t20170228_1467424.html

National Development and Reform Commission et al. (2015). Guidance on strengthening the construction of urban parking facilities. http://www.ndrc.gov.cn/zcfb/zcfbtz/201508/ t20150811_744943.html

Paliwal, R. (2006). EIA practice in India and its evaluation using SWOT analysis. Environmental Impact Assessment Review, 26(5), 492-510. https://doi.org/10.1016/j.eiar.2006.01.004

Parasol, M. (2017). The impact of China's 2016 cyber security law on foreign technology firms, and on China's big data and smart city dreams. Computer Law \& Security Review, 34(1), 67-98. https://doi.org/10.1016/j.clsr.2017.05.022

Polat, Z. A., Alkan, M., \& Sürmeneli, H. G. (2017). Determining strategies for the cadastre 2034 vision using an AHP-Based SWOT analysis: a case study for the Turkish cadastral and land administration system. Land Use Policy, 67, 151-166. https://doi.org/10.1016/j.landusepol.2017.05.004

Qin, H., \& Luo, W. (2014). Evaluation report on the level of informatization development in China (in Chinese).

Ruhlandt, R. W. S. (2018). The governance of smart cities: a systematic literature review. Cities, 81, 1-23.

https://doi.org/10.1016/j.cities.2018.02.014 
Saaty, T. L. (1977). A scaling method for priorities in hierarchical structures. Journal of Mathematical Psychology, 15(3), 234281. https://doi.org/10.1016/0022-2496(77)90033-5

Saaty, T. L., \& Vargas, L. G. (2012). Models, methods, concepts \& applications of the analytic hierarchy process. Springer Science \& Business Media. https://doi.org/10.1007/978-1-4614-3597-6

Scott, W. R. (2008). Institutions and organizations: ideas and interests. Sage Publications.

Şeker, Ş., \& Özgürler, M. (2012). Analysis of the Turkish consumer electronics firm using SWOT-AHP method. ProcediaSocial and Behavioral Sciences, 58, 1544-1554. https://doi.org/10.1016/j.sbspro.2012.09.1141

Sharifi, A. (2019). A critical review of selected smart city assessment tools and indicator sets. Journal of Cleaner Production, 233, 1269-1283. https://doi.org/10.1016/j.jclepro.2019.06.172

Shi, X. Y. (2016). Exploration of China's smart city development model in 2016. Communication World, 6, 24-25 (in Chinese). http://www.cnki.com.cn/Article/CJFDTotalJSTX201606017.htm

Shinno, H., Yoshioka, H., Marpaung, S., \& Hachiga, S. (2006). Quantitative SWOT analysis on global competitiveness of machine tool industry. Journal of Engineering Design, 17(3), 251-258. https://doi.org/10.1080/09544820500275180

Silva, B. N., Khan, M., \& Han, K. (2018). Towards sustainable smart cities: a review of trends, architectures, components, and open challenges in smart cities. Sustainable Cities and Society, 38, 697-713. https://doi.org/10.1016/j.scs.2018.01.053

Sindhu, S., Nehra, V., \& Luthra, S. (2017). Solar energy deployment for sustainable future of India: hybrid SWOC-AHP analysis. Renewable and Sustainable Energy Reviews, 72, 1138-1151. https://doi.org/10.1016/j.rser.2016.10.033

Söderström, O., Paasche, T., \& Klauser, F. (2014). Smart cities as corporate storytelling. City, 18(3), 307-320.

https://doi.org/10.1080/13604813.2014.906716

Sodiq, A., Baloch, A. A. B., Alim, S., Sezer, N., Mahmoud, S., Jama, M., \& Abdelaal, A. (2019). Towards modern sustainable cities: review of sustainability principles and trends. Journal of Cleaner Production, 227, 972-1001.

https://doi.org/10.1016/j.jclepro.2019.04.106

Sta, H. B. (2017). Quality and the efficiency of data in "SmartCities". Future Generation Computer Systems, 74, 409-416. https://doi.org/10.1016/j.future.2016.12.021
Starr, M., Joshi, O., Will, R. E., \& Zou, C. B. (2019). Perceptions regarding active management of the cross-timbers forest resources of Oklahoma, Texas, and Kansas: a SWOT-ANP analysis. Land Use Policy, 81, 523-530.

https://doi.org/10.1016/j.landusepol.2018.11.004

State Council (SC). (2014). National new urbanization plan (2014-2020). https://www.baidu.com/link?url=Hfx-FhfdpjzGHgKNLj0cwNUklbA4YxnB4saeepCciOTK-3E-cosGfiCp5WXYOrKzxGzfQFRq5YiGPNpeJwLy_qg4YK1bt33By7AEK 0DAB6W\&wd=\&eqid=a3ca45730040a0cd000000065d0e569d

SC. (2015). Approval for the establishment of 'Nanjing Jiangbei New Area'. http://www.gov.cn/xinwen/2015-07/20/content_2899677.htm

United Nations. (2014). World urbanization prospects: the 2014 revision, highlights, department of economic and social affairs. https://doi.org/10.4054/DemRes.2005.12.9

Vu, K., \& Hartley, K. (2018). Promoting smart cities in developing countries: policy insights from Vietnam. Telecommunications Policy, 42(10), 845-859. https://doi.org/10.1016/j.telpol.2017.10.005

Wang, S., \& Zheng, L. (2013). Comparison of evaluation system of smart cities in the world. E-Government, 1, 92-100 (in Chinese).

Wann-Ming, W. (2019). Constructing urban dynamic transportation planning strategies for improving quality of life and urban sustainability under emerging growth management principles. Sustainable Cities and Society, 44, 275-290.

https://doi.org/10.1016/j.scs.2018.10.015

Wu, H., Wang, J., Duan, H., Ouyang, L., Huang, W., \& Zuo, J. (2016). An innovative approach to managing demolition waste via GIS (geographic information system): a case study in Shenzhen city, China. Journal of Cleaner Production, 112, 494-503. https://doi.org/10.1016/j.jclepro.2015.08.096

Yang, T., Long, R., Cui, X., Zhu, D., \& Chen, H. (2017). Application of the public-private partnership model to urban sewage treatment. Journal of Cleaner Production, 142, 1065-1074. https://doi.org/10.1016/j.jclepro.2016.04.152

Yin, C., Xiong, Z., Chen, H., Wang, J., Cooper, D., \& David, B. (2015). A literature survey on smart cities. Science China Information Science, 58, 1-18.

https://doi.org/10.1007/s11432-015-5397-4

Zhao, S., Feng, L., \& Li, P. (2013). Building smart cities and solving "urban disease". Natural Resource Economics of China, 1, 50-52 (in Chinese).

\section{Appendix}

Table A1. Matrix of paired comparisons for SNC (one expert)

\begin{tabular}{|c|c|c|c|c|c|c|c|c|c|}
\hline Strengths & $\mathrm{S} 1$ & S2 & S3 & $\mathrm{S} 4$ & Weaknesses & $\mathrm{W} 1$ & W2 & W3 & W4 \\
\hline S1 & 1 & 1 & 3 & 1 & W1 & 1 & 3 & 1 & $1 / 5$ \\
\hline S2 & 1 & 1 & 5 & 3 & W2 & $1 / 3$ & 1 & $1 / 3$ & $1 / 4$ \\
\hline S3 & $1 / 3$ & $1 / 5$ & 1 & 1 & W3 & 1 & 3 & 1 & 1 \\
\hline S4 & 1 & $1 / 3$ & 1 & 1 & W4 & 5 & 4 & 1 & 1 \\
\hline Opportunities & $\mathrm{O} 1$ & $\mathrm{O} 2$ & $\mathrm{O} 3$ & $\mathrm{O} 4$ & Threats & $\mathrm{T} 1$ & $\mathrm{~T} 2$ & $\mathrm{~T} 3$ & $\mathrm{~T} 4$ \\
\hline O1 & 1 & 5 & 5 & 5 & $\mathrm{~T} 1$ & 1 & 4 & 5 & 1 \\
\hline $\mathrm{O} 2$ & $1 / 5$ & 1 & 1 & 1 & $\mathrm{~T} 2$ & $1 / 4$ & 1 & 3 & $1 / 4$ \\
\hline $\mathrm{O} 3$ & $1 / 5$ & 1 & 1 & $1 / 3$ & T3 & $1 / 5$ & $1 / 3$ & 1 & $1 / 3$ \\
\hline $\mathrm{O} 4$ & $1 / 5$ & 1 & 3 & 1 & $\mathrm{~T} 4$ & 1 & 4 & 3 & 1 \\
\hline
\end{tabular}


Table A2. Intensity for strength factors and groupings in SNC (one expert)

\begin{tabular}{|c|c|c|c|c|c|c|}
\hline \multirow{2}{*}{ Objective } & $\begin{array}{c}\text { Importance of } \\
\text { objectives }\end{array}$ & Factors & $\begin{array}{c}\text { Local } \\
\text { importance of } \\
\text { factors }\end{array}$ & Scores of factors & Factor intensity & Group intensity \\
\hline \multirow{2}{*}{ S } & 0.28 & S1 & 0.289 & 4 & 1.156 & 0.811 \\
\cline { 3 - 6 } & & S2 & 0.432 & 3 & 1.296 \\
\cline { 3 - 6 } & & S3 & 0.112 & 1 & 0.112 \\
\cline { 3 - 6 } & & S4 & 0.167 & 2 & 0.334 \\
\hline
\end{tabular}

Table A3. Intensity for weakness factors and groupings in SNC (one expert)

\begin{tabular}{|c|c|c|c|c|c|c|}
\hline \multirow{2}{*}{ Objective } & $\begin{array}{c}\text { Importance of } \\
\text { objectives }\end{array}$ & Factors & $\begin{array}{c}\text { Local } \\
\text { importance of } \\
\text { factors }\end{array}$ & Scores of factors & Factor intensity & Group intensity \\
\hline \multirow{2}{*}{$\mathrm{W}$} & \multirow{2}{*}{0.22} & $\mathrm{~W} 1$ & 0.218 & -2 & -0.436 \\
\cline { 3 - 6 } & & $\mathrm{W} 2$ & 0.086 & -1 & -0.086 \\
\cline { 3 - 6 } & & $\mathrm{W} 3$ & 0.271 & -3 & -0.813 \\
\cline { 3 - 6 } & & W4 & 0.425 & -4 & -1.7 \\
\hline
\end{tabular}

Table A4. Intensity for opportunity factors and groupings in SNC (one expert)

\begin{tabular}{|c|c|c|c|c|c|c|}
\hline \multirow{2}{*}{ Objective } & $\begin{array}{c}\text { Importance of } \\
\text { objectives }\end{array}$ & Factors & $\begin{array}{c}\text { Local } \\
\text { importance of } \\
\text { factors }\end{array}$ & Scores of factors & Factor intensity & Group intensity \\
\hline \multirow{2}{*}{$\mathrm{O}$} & 0.27 & $\mathrm{O} 1$ & 0.619 & 2 & 1.238 & 0.471 \\
\cline { 3 - 6 } & & $\mathrm{O} 2$ & 0.124 & 2 & 0.248 \\
\cline { 3 - 6 } & & $\mathrm{O} 3$ & 0.094 & 1 & 0.094 \\
\cline { 3 - 6 } & & $\mathrm{O} 4$ & 0.163 & 1 & 0.163 \\
\hline
\end{tabular}

Table A5. Intensity for threat factors and groupings in SNC (one expert)

\begin{tabular}{|c|c|c|c|c|c|c|}
\hline \multirow{2}{*}{ Objective } & $\begin{array}{c}\text { Importance of } \\
\text { objectives }\end{array}$ & Factors & $\begin{array}{c}\text { Local } \\
\text { importance of } \\
\text { factors }\end{array}$ & Scores of factors & Factor intensity & Group intensity \\
\hline \multirow{2}{*}{$\mathrm{T}$} & 0.23 & $\mathrm{~T} 1$ & 0.453 & -2 & -0.906 & -0.361 \\
\cline { 3 - 6 } & & $\mathrm{T} 2$ & 0.262 & -1 & -0.262 \\
\cline { 3 - 6 } & & $\mathrm{T} 3$ & 0.167 & -1 & -0.167 \\
\cline { 3 - 6 } & & $\mathrm{T} 4$ & 0.118 & -2 & -0.236 \\
\hline
\end{tabular}




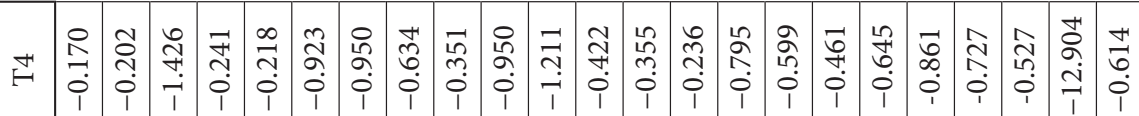

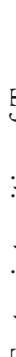

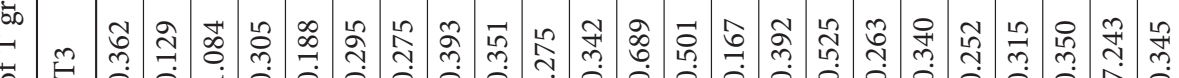

H

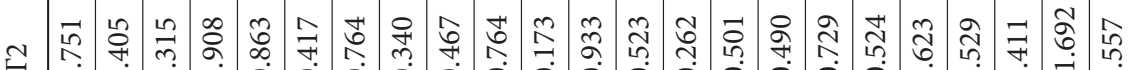

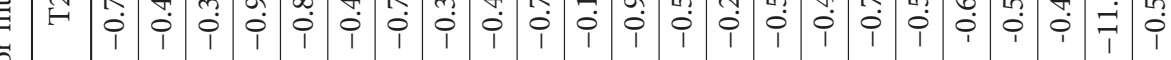

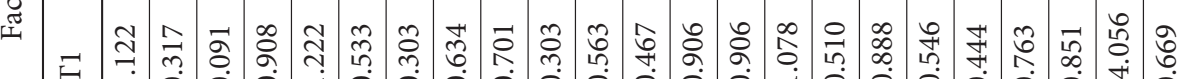

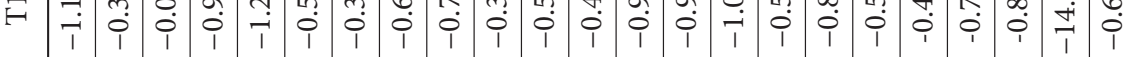

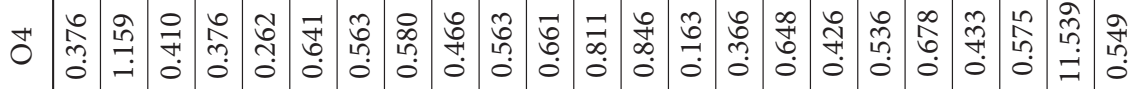
亏े

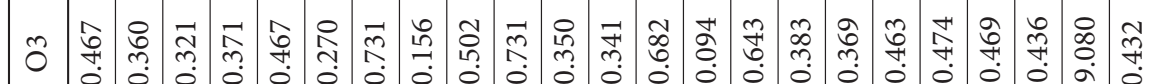
(1)

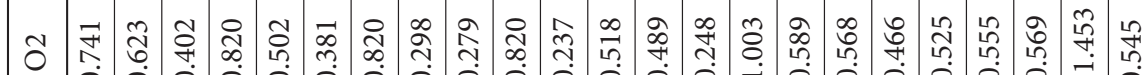

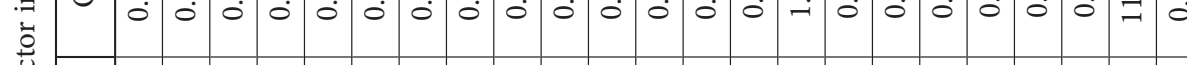
焉

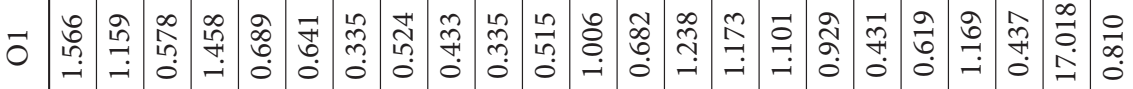

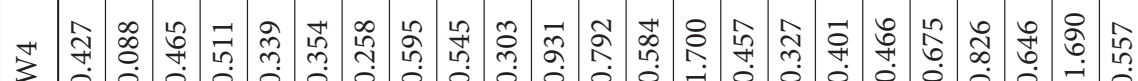
छे

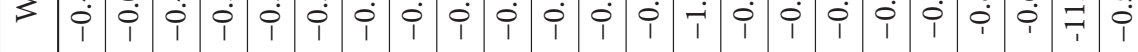

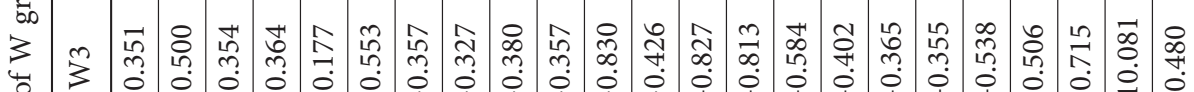

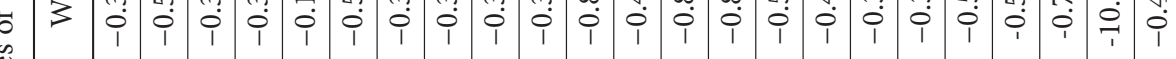

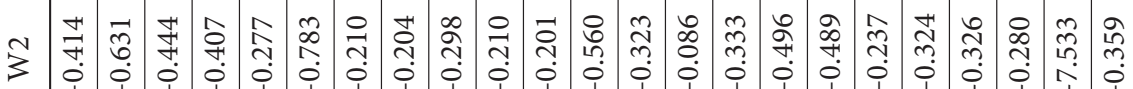

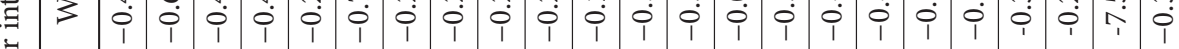
蒙

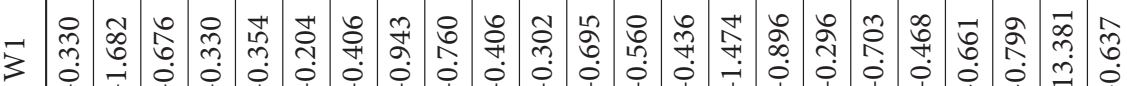

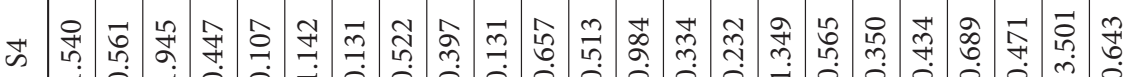
苛

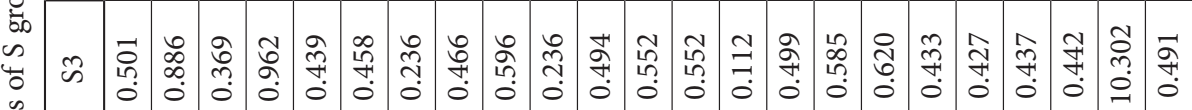
$\stackrel{\mathscr{?}}{=}$

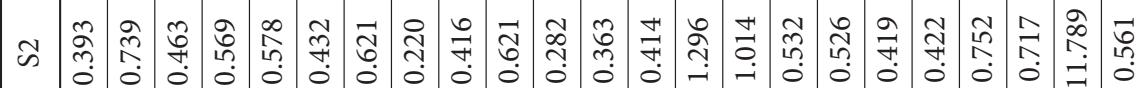
妾 通

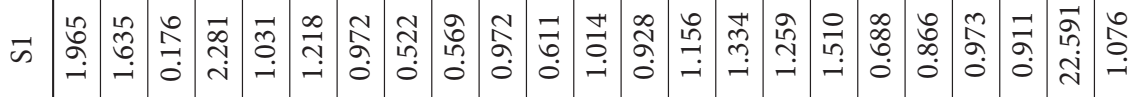

:

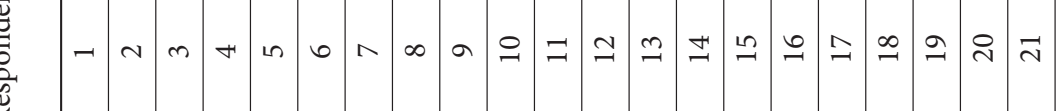




\section{Notations}

Abbreviations:

SWOT - Strength, Weakness, Opportunity, and Threat;

AHP - Analytic Hierarchy Process;

SNC - Smart Nanjing City;

NGIT - New Generation of Information Technology;

IoT - Internet of Things;

MOHURD - Ministry of Housing and Urban-Rural Development;

SC - State Council;

NPG - People’s Government of Nanjing;

NIPC - Nanjing Investment Promotion Center;

PPP - Public-Private Partnership;

$5 \mathrm{G}$ - Fifth Generation. 